\title{
THE NEPHROTIC SYNDROME IN CHILDREN. AN INTERPRE- TATION OF ITS CLINICAL, BIOCHEMICAL, AND RENAL HEMODYNAMIC FEATURES AS VARIATIONS OF A SINGLE TYPE OF NEPHRON DISEASE 1, 2
}

\author{
By JACK METCOFF, W. M. KELSEY, ${ }^{3}$ and C. A. JANEWAY with the technical \\ ASSISTANCE OF AUDREY ANDREWS, MARGARET HASSON, AND \\ BERNICE GOLDBERG
}

(From The Department of Pediatrics, Harvard Medical School, and The Children's Medical Center, Boston)

(Submitted for publication September 25, 1950 ; accepted, March 12, 1951)

It is the purpose of this report to describe and interpret the varied renal hemodynamic patterns and associated clinical and biochemical features observed in 29 children with the nephrotic syndrome studied between January, 1949, and June, 1950.

Cases of the "nephrotic syndrome" present certain uniform and consistent clinical features (1), but their separation into two groups, "nephrosis" and the "nephrotic stage of nephritis," has been rather arbitrary and frequently difficult. Normal or supernormal renal function (2) on the one hand, and hematuria, hypertension, and azotemia (3-6) on the other, have been the classical criteria for this distinction. However, review of the clinical course of patients classified as "nephrosis" with subsequent complete remission, has shown that moderate hematuria, hypertension and azotemia were common transiently observed phenomena (710). Moreover, serial renal function studies have demonstrated varying degrees of functional impairment in patients clinically classified as instances of either nephrosis $(11,12)$ or the nephrotic stage of glomerulonephritis (13-15).

This study was undertaken in order to determine :

1 These studies were supported by grants from Mead Johnson \& Co. and from the National Institutes of Health, U. S. Public Health Service.

2 Presented in part before the Society of Pediatric Research, French Lick, Ind., May 1950, and the Sixth International Congress of Pediatrics, Zurich, Switzerland, July 1950.

3 Post-Doctorate Research Fellow of the National Institutes of Health, U. S. Public Health Service; Asst. Professor of Pediatrics, Bowman Gray School of Medicine, Winston-Salem, N. C. (on leave of absence).
1) If measurements of renal function would assist in the early differentiation of benign nephrosis from progressive nephritis,

2) if such a differentiation were valid physiologically, and

3) if studies of renal function would help to elucidate the pathogenesis of the nephrotic syndrome. A preliminary report has been published (16).

Lacking the biopsy material which would permit morphologic description of the diseased organ, the results of our physiologic studies seem to corroborate an earlier suggestion, based on pathologic studies, that both "degenerative" lipoid nephrosis and "inflammatory" glomerulonephritis are characterized by anatomical lesions and disturbances in function which are identical in kind, but different in degree (17). The data of this report indicate that the glomerulus is a primary site of the disease process, but the syndrome is frequently characterized by reversible metabolic and hemodynamic rather than solely by irreversible anatomic damage of the nephron.

\section{CLINICAL MATERIAL AND PROCEDURES}

\section{General plan of study}

Estimations of glomerular filtration rates (GFR), renal plasma flow (RPF), and maximal tubular excretory capacity ( $\left.\mathrm{Tm}_{\mathrm{PAB}}\right)$, were made in 29 nephrotic children, with more than one series of simultaneous biochemical and renal functional studies in $\mathbf{1 7}$ of these patients. In all, 53 estimations of renal function and biochemical status were made and correlated with clinical courses. Of the 29 patients, only two were over 6.5 years of age at the time of first admission. Three patients were over 6.5 years of age at the time initial renal function studies 
TABLE I

Clinical status of all nephrotic patients observed during interval January, 1949-June, 1950

\begin{tabular}{l|c|c|c|c|c|c}
\hline \hline \multirow{2}{*}{$\begin{array}{c}\text { Nephrotic } \\
\text { patients }\end{array}$} & No. of \\
patients & Males & \multicolumn{4}{|c}{ Clinical status* } \\
\cline { 2 - 7 } & Remission & Good & Poor & Dead \\
\hline This report & 29 & 11 & $10 \dagger$ & 6 & 3 & $10 \ddagger$ \\
\hline $\begin{array}{l}\text { Remainder } \\
\text { clinic } \\
\text { group }\end{array}$ & 61 & 45 & 20 & 22 & 9 & 10 \\
\hline Total & 90 & 56 & 30 & 28 & 12 & 20 \\
\hline Per cent & 100 & 62 & 33 & 31 & 14 & 22 \\
\hline
\end{tabular}

* Remission $=$ No edema, normal diet, full activity, minimal to absent proteinuria for at least two months.

Good = Edema, proteinuria, hypoproteinuria, hyperlipemia, no anemia, acidosis, azotemia. Urine specific gravity 1.018 or more.

Poor = Nephrotic syndrome with anemia, acidosis, azotemia, urine specific gravity "fixed" 1.010.

$\dagger$ Three patients have relapsed since this report was submitted for publication.

$\ddagger$ Two patients died shortly after this report was prepared for publication.

were done. All other patients were less than five years of age. Omitting two extremes of age, the mean age of the group was 3.3 years and median age 3.0 years. Comments on the physiological disturbances of electrolytes and body fluids will be the subject of another report.

Appraisal of the factors which determined the selection of the particular patients for study from our clinic group was extremely difficult. Patients usually appeared in the clinic soon after manifestations of the disease were noted. The observed group of patients, therefore, was not unduly weighted by the usual preponderance of severe or advanced cases commonly noted in hospital samples. An attempt was made to select for study children with nephrosis and both with and without hematuria and/or azotemia, and with active disease of varying duration.

The sex distribution and clinical status of the patients studied is related to that of the total group of 90 nephrotic children observed in this clinic during the same time interval (Table $\mathrm{I}$ ). The inclusion of fewer males in the study sample may be attributed to reluctance to catheterize male children with marked edema of the genitalia.

\section{Blood samples}

Serum or plasma concentrations of the test substances employed were, in the majority of instances, measured in "arterial" blood obtained from capillary puncture. An inlying venous needle with fitted stylette was frequently used in larger children for sampling. Approximately 0.5 $\mathrm{ml}$. whole blood was collected in $10 \mathrm{~cm}$. long, $3 \mathrm{~mm}$. bore, chemically clean capillary tubes-filled by direct capillarity from finger puncture (18). A drop of dilute heparin was used to wet the bore when plasma was desired; however, a considerably better yield of serum was usually obtained from the same aliquot of non-heparinized blood. The capillary tube, when filled, was capped with flanged flexible rubber caps. ${ }^{4}$ Twenty to 40 seconds were usually required to fill a tube. After centrifugation for $30 \mathrm{~min}$ utes at $2,500 \mathrm{rpm}$, the tube was scratched $1 \mathrm{~mm}$. above the level of packed cells, the cap at the serum end of the tube removed, and the serum-containing portion of the tube carefully broken off and recapped. The heparinized blood hematocrit was read directly by alignment of the tube against a millimeter rule. Approximately $0.2-0.3 \mathrm{ml}$. serum was thus available per tube. Two or three microtubes obtained per period sufficed for duplicate determinations. Where simultaneous thiosulfate, inulin, and $\mathrm{PAH}$ clearances were done, four or five tubes were obtained per period. The relatively small yield of serum, however, necessitated micromodification of usual procedures.

\section{Renal function studies}

Patients were hospitalized and confined to bed for 18 to 24 hours prior to study. Fluids were allowed ad lib. No food was offered during the eight hour period preceding the test. All clearance studies were begun at approximately 8:30 a.m. Using a dose based on age, premedication with morphine sulfate and atropine sulfate was employed in about two-thirds of the studies in order to reduce apprehension in uncomfortable, edematous children. In general, commonly accepted techniques with few minor modifications were employed. A single injection of thiosulfate and constant infusion of inulin and $\mathrm{PAH}$ were used. Urine was collected through an indwelling, multi-eyed 8-14F catheter. The bladder was washed at the end of each period with sterile distilled water and with air. Urine volumes, including wash, were recorded to the nearest $0.1 \mathrm{ml}$. Thirty minutes were allowed for equilibration after the priming injection. Consecutive 15 minute collections of urine were then made for six to ten periods. In the majority of instances, blood samples were obtained at approximately $30,60,90,120$, 150 , and 180 minutes and midpoint values of each period determined by interpolation. It was not possible to correct for urine delay time. A control venous blood sample was obtained under oil for blank determination and analysis of various serum chemical components. All sera and urine aliquots for thiosulfate and inulin analysis were precipitated within two to four hours. Analyses were completed within 24 hours.

\section{METHODS}

Glomerular filtration rate (GFR) was determined using a single injection of sodium thiosulfate $\left(\mathrm{Na}_{2} \mathrm{~S}_{2} \mathrm{O}_{3} \cdot 5 \mathrm{H}_{2} \mathrm{O}\right)$

4 Obtained from the West Company, 1117 Shakamaxon St., Philadelphia, Pa. 
(19) in the initial 19 observations. In the majority of instances, simultaneous inulin and thiosulfate clearances were measured. Approximately $30 \mathrm{mM}$. (8 gm.) $\mathrm{Na}_{2} \mathrm{~S}_{2} \mathrm{O}_{3}$. $5 \mathrm{H}_{2} \mathrm{O}$ per square meter of surface area were administered as a freshly prepared $10-17 \%$ solution. Unpleasant reactions to relatively rapid infusions $(6-10 \mathrm{ml} . / \mathrm{min}$.) of this solution were rare. Concentrations of thiosulfate in serum and urine were determined in duplicate, with micromodification for serum, according to the standard periodate titrometric method. Semilogarithmic plot of urinary thiosulfate excretion and of serum concentrations against time usually followed decremental straight lines of varying slope. Initial serum concentrations approximating $40-60 \mathrm{mg} . / 100 \mathrm{ml}$. were usually obtained.

The inulin clearance determined by a constant infusion technique was measured simultaneously with thiosulfate and PAH clearances in the majority of instances. 5 Serum concentrations of inulin usually approximated $20-80 \mathrm{mg}$./ $100 \mathrm{ml}$., and of PAH, $1.5-4.0 \mathrm{mg} . / 100 \mathrm{ml}$. Inulin in serum and urine was determined by method of Roe, Epstein, and Goldstein (21) with minor modification. The standard acid $\mathrm{CdSO}_{4}$ protein precipitating solution (22) was found to give as satisfactory recoveries as the Somogyi reagents, and therefore this deproteinizing agent was used. For precipitation, serum in the microtubes was transferred by capillarity into a calibrated $0.2 \mathrm{ml}$. (normax grade) $\Phi$ pipette and delivered with three washings into $2.0 \mathrm{ml}$. distilled water contained in a 3-4 ml., $10 \mathrm{~mm}$. bore, precipitin tube. The standard $\mathrm{CdSO}_{4}$ precipitation was completed using one-tenth quantities of reagents. After standing 10 minutes, the precipitate was compacted by centrifugation for 20 minutes at $2,000 \mathrm{rpm}$. Duplicate tubes were prepared for each specimen and afforded sufficient supernatant for duplicate determinations of $\mathrm{PAH}$ and inulin. Optical density of color for inulin and PAH was determined in a Coleman Junior spectrophotometer. Maximum absorption of the resorcinol-inulin complex occurred at $510 \mathrm{~m} \mu$. Standard recoveries were determined with each series of analyses and an average constant in

5 A comparison of 118 simultaneous thiosulfate and inulin clearance periods indicated fairly good agreement at all clearance levels, although the quantitative significance of values obtained at apparently low levels of filtration is questionable. Occasional widely discrepant values were noted. Thiosulfate clearances were usually greater than those of inulin. The average clearance ratio $\frac{\text { thiosulfate }}{\text { inulin }}$ for all periods was 1.1. Greater discrepancies were observed with the highest clearance values. The correlation coefficient of thiosulfate versus inulin clearance was $0.88 \pm$ 0.09 . The mean discrepancy between all values for simultaneous thiosulfate versus inulin clearance was $5.5 \pm 3.9$ $\mathrm{ml} . / \mathrm{min}$. The ratio, $\frac{\mathrm{C} \text { thiosulfate, }}{\mathrm{C} \text { inulin }}$ was apparently independent of serum concentration of thiosulfate, $r=0.36$, in contrast to observations in pregnant women (20). terms of optical density was derived. The constant, rather than a standard transmission curve, was used for calculation. Little variation in constants was observed in more than 70 multiple recovery determinations.

Constant infusions of $\mathrm{PAH}$ following a priming dose were used to measure renal plasma flow (RPF) and maximal tubular excretory capacity ( $\mathrm{Tm}$ ) (23). PAH was diluted in $5 \%$ glucose for clearance and in distilled $\mathrm{H}_{2} \mathrm{O}$ for $\mathrm{Tm}$ determinations. Priming doses were diluted in distilled $\mathrm{H}_{2} \mathrm{O}$. The observed PAH clearances may be low because of the unrecognized reaction of $\mathrm{PAH}$ with glucose (24). In the initial renal function studies, glomerular filtration rates were determined with thiosulfate immediately prior to RPF and subsequent $\mathrm{Tm}$ periods. Thereafter, simultaneous inulin and PAH clearance and saturation studies were carried out. Concentrations of $\mathrm{PAH}$ in serum and urine were determined by micromodification of a standard method (22). At high serum concentrations, $1.0 \mathrm{ml}$. aliquots of the supernatant solution obtained after precipitation (vide supra) were diluted 20 times with distilled water and color was developed in 10 $\mathrm{ml}$. aliquots by standard macro technique. Color was read at $540 \mathrm{~m} \mu$ in the Coleman Junior spectrophotometer. Standard recoveries and determination of recovery constants were carried out with each series of analyses. Serum blank was determined by difference. Urine blanks were found to be negligible at the dilutions used $(1: 2,500$ 10,000).

Impairment of the renal tubules may decrease the extraction ratio and may invalidate the use of uncorrected clearances for the measurement of renal plasma flow. Renal PAH extraction data are not yet available in infants and children. Cargill has reported values for renal $\mathrm{PAH}$ extraction of normal adult patients and of nine glomerulonephritics with varying levels of observed $\mathrm{PAH}$ clearance (25a). An exponential extraction curve has been constructed from these data and used to "correct" observed RPF for approximate extraction in order to afford an estimate of "corrected" renal plasma flow $\left(R P F_{c}\right)$. An assumption of this type has obvious limitations, but occasionally seemed to yield a more reasonable range of magnitude for renal plasma flow.

\section{Estimation of surface area}

The estimation of surface area in the persistently edematous child presents an obvious problem, and ideal weight in relation to height and age is unreliable in children whose disease is of sufficiently long duration to impair linear growth and induce chronic malnutrition with wasting. I reasonable approximation of "non-edematous weight" usually was derived by comparing the observed volume of distribution $\left(V_{D}\right)$ of thiosulfate in the edematous patient to a presumed "normal" $V_{D}$ estimated from thiocyanate space regression equations for height (25b). $\mathrm{SCN}$ and $\mathrm{S}_{2} \mathrm{O}_{3}$ may occupy somewhat different apparent distributions in view of the protein binding of SCN (26); 
neither accurately measures extracellular fluid volume. ${ }^{6}$ Occasionally such estimation of surface area (SA) was obviously inadequate. Post-diuresis weight then was used to correct previous measurements of renal function to unit values. Using the derived value for "non-edematous weight," SA was estimated either by calculation or from nomograms constructed from the standard DuBois relationship: $\mathrm{SA}=\mathrm{W}^{0.425} \times \mathrm{H}^{0.726} \times 71.84$.

\section{Other measurements}

Serum proteins were determined by micro-Kjeldahl analysis. Serum NPN (27), gasometric $\mathrm{CO}_{2}$ content (28), $\mathrm{pH}$ (29), and cholesterol (30), were determined by standard methods. Plasma volume determinations, ${ }^{7}$ using Evans blue (T-1824) and a modification of an acetone extraction technique (31), were carried out in all patients immediately prior to clearance studies.

\section{RESULTS}

\section{Clinical observations}

A summary of the clinical features of patients studied by clearance techniques is given in Table II.

- The use of $V_{D}$ thiosulfate for the estimation of "nonedematous weight" is indicated by the following example:

Patient CB, Male-Age 1-11/12

Edematous-Before diuresis

Height $=90.8 \mathrm{~cm}$.

Initial volume distribution $\left(\mathrm{V}_{\mathrm{D}}\right) \mathrm{Na}_{2} \mathrm{~S}_{2} \mathrm{O}_{3}=8.26 \mathrm{~L}$.

Predicted normal $V_{D}$ for height* ${ }^{*}=3.32 \mathrm{~L}$.

Estimated volume edema (predicted decrease $V_{D}$ )

Estimated weight edema $=4.94 \times 1.02=5.04 \mathrm{Kg}$. Actual weight $\quad 17.70 \mathrm{Kg}$.

Edema

5.04

Estimated non-edematous weight

for predicted change in $V_{D} \quad 12.66 \mathrm{Kg}$.

* Where $\mathrm{V}_{\mathrm{D}}(\mathrm{NaScN})=-6.14+0.1042 \mathrm{H}$ for $\mathrm{SA}=0.5$ $-1.2 \mathrm{M}^{2}(25 b)$.

Non-edematous-After diuresis

Height $=91.5 \mathrm{~cm}$.

Final volume distribution $\left(\mathrm{V}_{\mathrm{D}}\right) \mathrm{Na}_{2} \mathrm{~S}_{2} \mathrm{O}_{3}$

Observed decrease $\left(V_{D}\right), 8.26-3.23$

Estimated weight change from observed change in $V_{D}=5.03 \times 1.02$

Predicted weight from actual $\mathrm{V}_{D}$,

$17.70-5.13 \quad=12.57 \mathrm{Kg}$.

Observed non-edematous weight $=11.88 \mathrm{Kg}$.

Error of prediction $\quad=\overline{0.69 \mathrm{Kg} .} 6 \%$

Estimated ideal weight from height $=13.50 \mathrm{Kg}$.

11.88

Error of prediction

$=1.62 \mathrm{Kg} .14 \%$

7 Detailed data will be the subject of another report.
The onset of symptoms was estimated from history. Since many of the children who developed the disease were quite young, observations of growth and physical status, occasionally including blood pressure and urine examination, had often been made by the family physician prior to onset of the nephrotic syndrome. When available, such information confirmed the absence of antecedent renal disease. Since renal disease of this type in children is usually associated with marked loss of appetite, lassitude, oliguria, and personality change or irritability before edema is more than suspected, parents were apt to consult their physician with the advent of definite edema. In no instance was gross hematuria, elevated blood pressure, or cardiac failure observed by the first physician to see the patient in the early phases of the disease. Upper respiratory or other infections preceded the onset of the nephrotic syndrome in only seven of 29 patients.

All patients with the nephrotic syndrome at the time of initial observation in this clinic presented the rapid or insidious onset of edema as a chief complaint. Oliguria, marked proteinuria, absence of gross or marked microscopic hematuria, hypoproteinemia (micro-Kjeldahl), and elevation of serum cholesterol were constant features. Cardiac enlargement was not observed but variable values for blood pressure and NPN were obtained in all phases of the disease (Table II). Spontaneous diuresis, frequently observed in the first weeks or months of the disease, was usually associated with temporary improvement in the values for urine and blood constituents.

\section{Hematuria, azotemia and anemia}

The clinical data indicated that hypertension, microscopic hematuria, and/or slight to moderate azotemia during the early months of the disease often were unreliable indices of the functional state of the kidney or subsequent course of the disease. However, essentially hyperbolic correlation was found between elevation of the NPN and diminution of GFR (Figure 1) as previously noted (32-34). Similarly, the occurrence and extent of acidosis, as indicated by serum $\mathrm{CO}_{2}$ content and $\mathrm{pH}$, was found to correlate roughly with reduction of GFR $(35,36)$ (Figure 2). The simultaneous variation of $\mathrm{pH}, \mathrm{CO}_{2}$ content and non- $\mathrm{CO}_{2}$ serum buffers in relation to GFR was expressed according 


\begin{tabular}{|c|c|c|c|c|c|c|c|c|c|c|c|c|c|c|}
\hline$\approx$ & \multirow{3}{*}{ 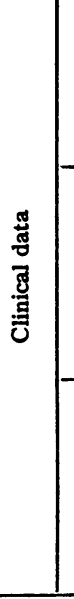 } & 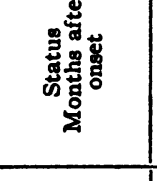 & 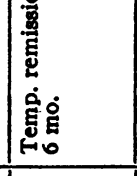 & 总 & 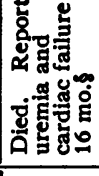 & 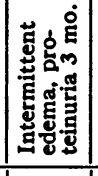 & 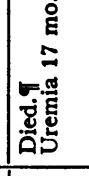 & 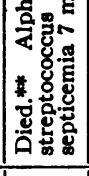 & 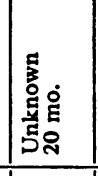 & 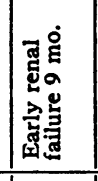 & 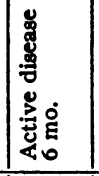 & 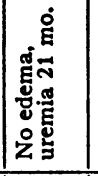 & 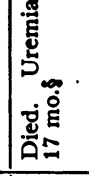 & 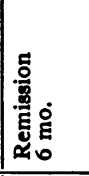 \\
\hline 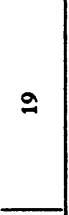 & & 逽 & 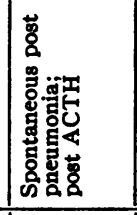 & 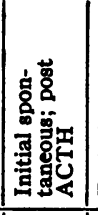 & 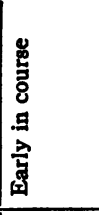 & 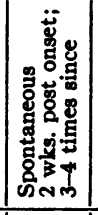 & 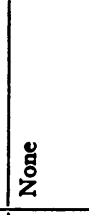 & 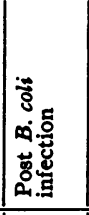 & 参 & 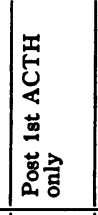 & 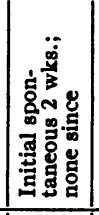 & 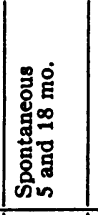 & 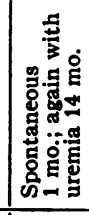 & 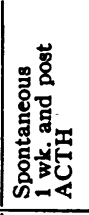 \\
\hline$\underline{0}$ & & 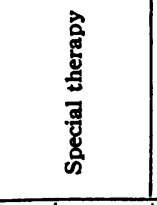 & 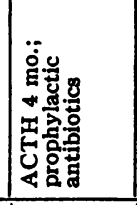 & $\mid$ & 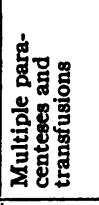 & 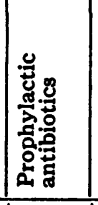 & 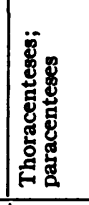 & 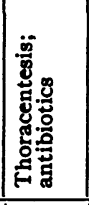 & 产 & 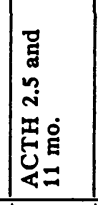 & 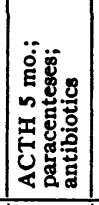 & & 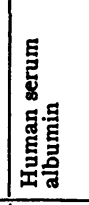 & 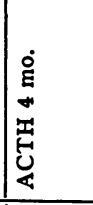 \\
\hline$=$ & \multirow{10}{*}{ 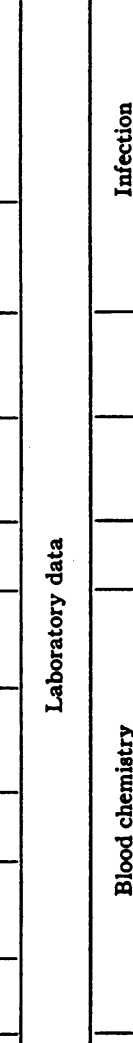 } & 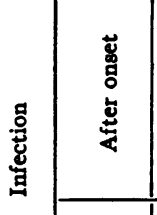 & 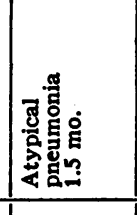 & 兽 & 总 & $\overline{\tilde{s}}$ & 总 & 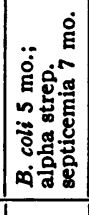 & 总 & 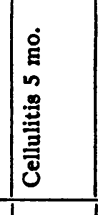 & 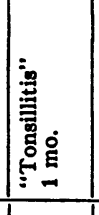 & 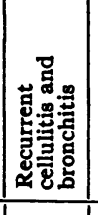 & 送 & 善 \\
\hline 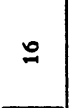 & & 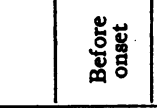 & 量 & 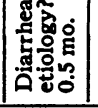 & : & 总 & 兽 & 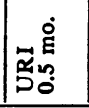 & $\mid$ & 高 & 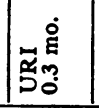 & 总 & 总 & 窨 \\
\hline$\underline{n}$ & & 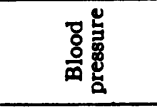 & 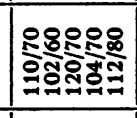 & 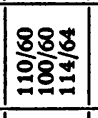 & 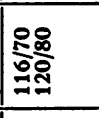 & 总 & 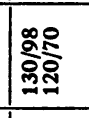 & 总 & 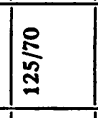 & 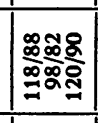 & 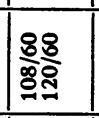 & $\mid$ & $\mid$ & 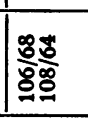 \\
\hline$=$ & & 曽 & \pm+ \pm & $\pm+\infty$ & \pm \pm & \pm & \pm \pm & $\stackrel{+}{+}$ & ${ }_{m}^{+}$ & \pm++ & $\pm+\infty$ & $\mid$ & + \pm & ${ }_{m+1}^{+}$ \\
\hline 2 & & 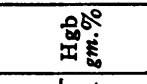 & $\mid$ & $\mid$ & $\mid$ & İ & 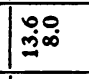 & $\mid \stackrel{0}{0}$ & 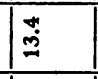 & $\mid$ & 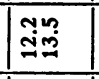 & $\mid$ & 10 & 型 \\
\hline$\simeq$ & & 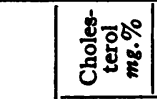 & 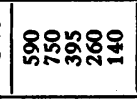 & 㗁器 & $\dddot{q}$ & is & & & $¥$ & 8 & 웅뭉 & 数? & & $1 \%$ \\
\hline$=$ & & 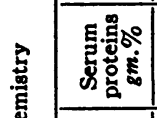 & 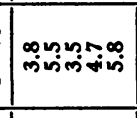 & 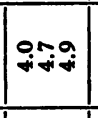 & 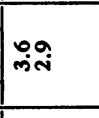 & 7 & 觯 & 7 & $\ddot{\circ}$ & 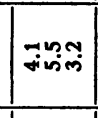 & $7 \%$ & 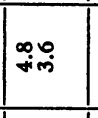 & 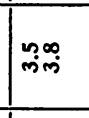 & 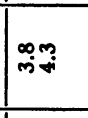 \\
\hline 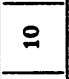 & & $\begin{array}{ll} \\
\end{array}$ & 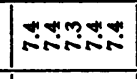 & 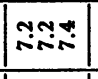 & $\approx \approx$ & $:$ & 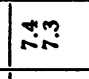 & & $:$ & $\mid$ & $\mid$ & $\mid x=1$ & 洪 & 20 \\
\hline$a$ & & 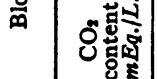 & 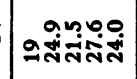 & $\mid$ & $\stackrel{m}{\infty}$ & $\underset{\substack{\infty \\
\dot{\alpha}}}{ }$ & 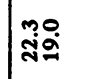 & & $\frac{3}{\pi}$ & 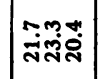 & 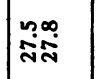 & 宓 & 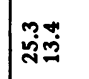 & 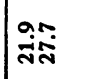 \\
\hline$\infty$ & & 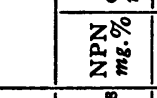 & 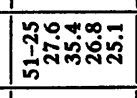 & 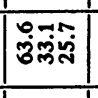 & 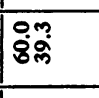 & $\ddot{\text { i }}$ & ప艹 & 萻 & 兽 & $\mid$ & 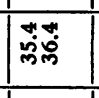 & $\mid$ & 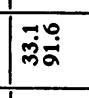 & |ீ:8 \\
\hline - & & s. & $10+\infty m$ & $|+\infty|$ & $1+\infty$ & $\tilde{\delta}$ & 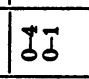 & $I_{2}^{2}$ & $\tilde{\delta}$ & $|\because-1|$ & $10 I$ & $\mid \bar{d} \vec{\delta}$ & $10_{-i}^{\infty}$ & ang \\
\hline$\circ$ & & 㩊 & 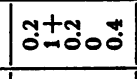 & 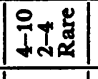 & IN & $I$ & \begin{tabular}{|l}
0 \\
ond \\
\end{tabular} & $\%$ & $\frac{9}{8}$ & 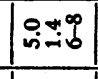 & \$̈0 & กิ่ & 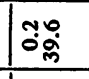 & no \\
\hline n & & 是: & $a$ & $\mid \begin{array}{l}++ \\
m\end{array}$ & +⿱ & \pm & +++ & \pm & I & $\infty_{\infty} \infty \pm+$ & $\mid$ & $\mid$ & 然 & \pm 0 \\
\hline . & \multicolumn{2}{|c|}{ 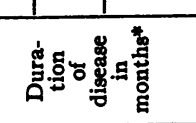 } & 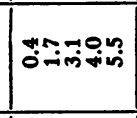 & 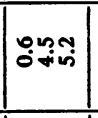 & 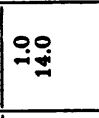 & $\stackrel{9}{i}$ & $\log _{i}$ & $\dddot{q}$ & i & 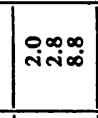 & ño & 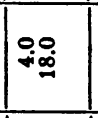 & 我禺 & $9 ;$ \\
\hline m & \multicolumn{2}{|c|}{ 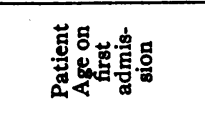 } & - & 赵: & ن: & \&: & wis & 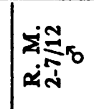 & مि & 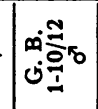 & 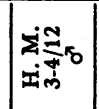 & 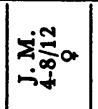 & 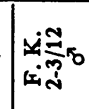 & 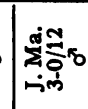 \\
\hline$\approx$ & \multicolumn{2}{|r|}{ 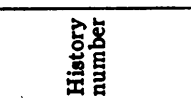 } & 潡 & 颜 & 商 & 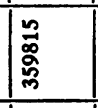 & 譬 & 雚 & 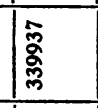 & 聪 & 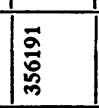 & 茼 & 善 & 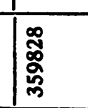 \\
\hline- & & - & N & $m$ & * & in & 0 & - & $\infty$ & a & 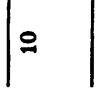 & $=$ & $\simeq$ \\
\hline
\end{tabular}




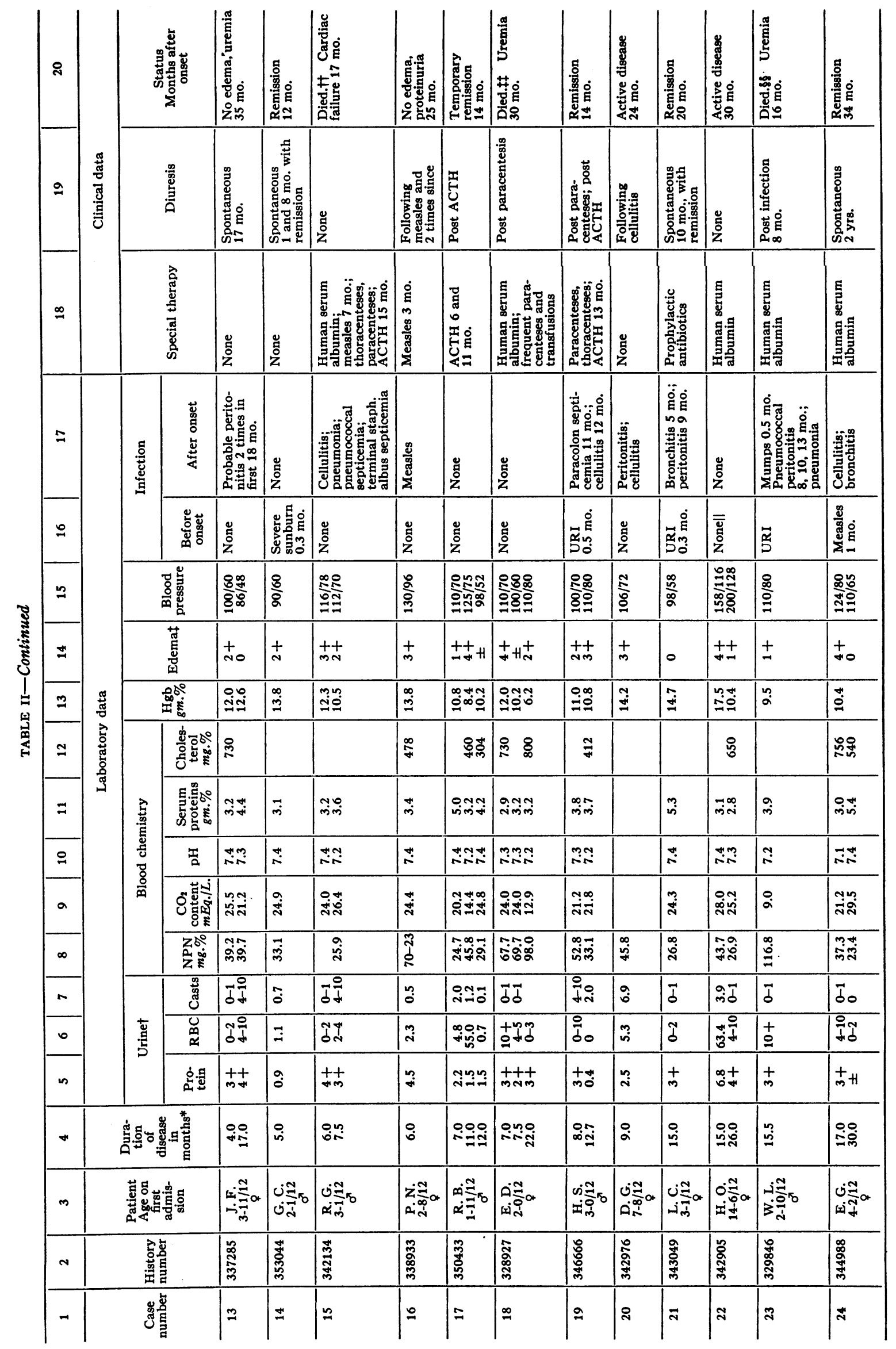




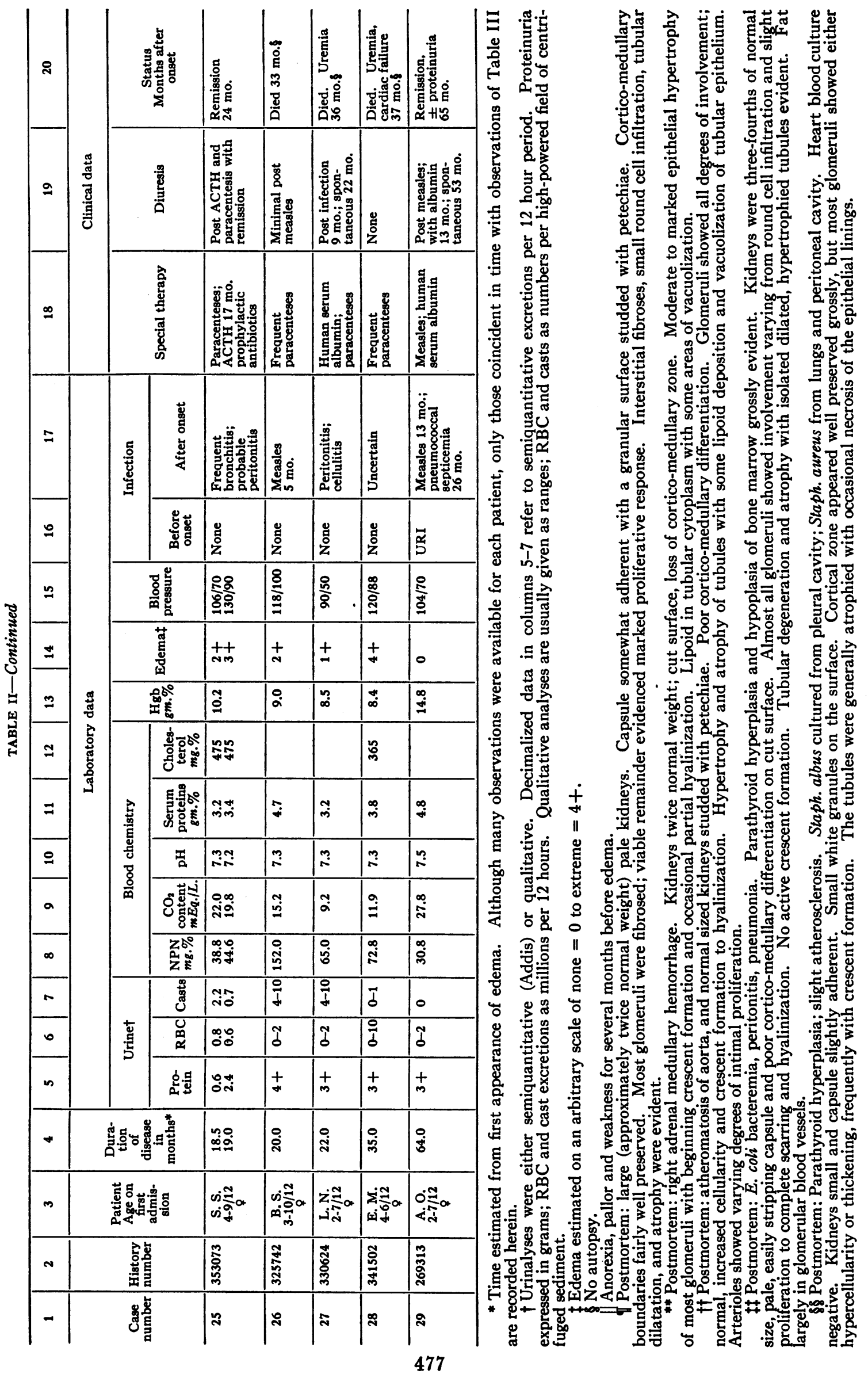


RELATION OF SERUM NON-PROTEIN NITROGEN TO SIMULTANEOUSLY DETERMINED GLOMERULAR FILTRATION RATE IN CHILDREN WITH THE NEPHROTIC SYNDROME

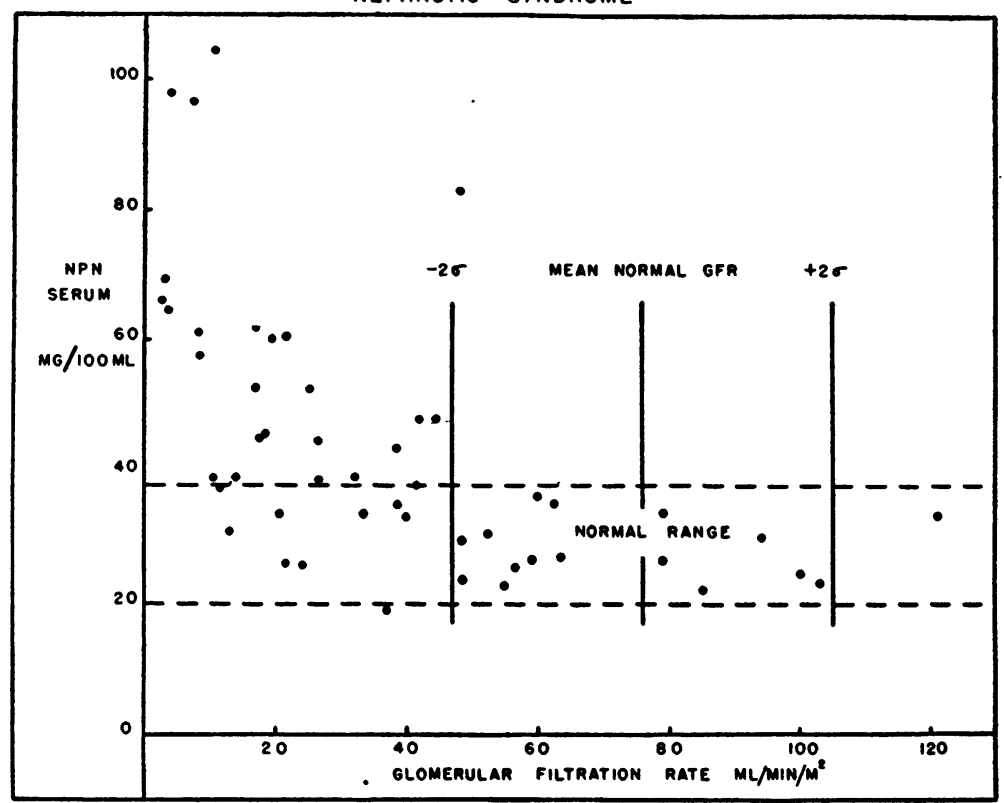

Fig. 1.

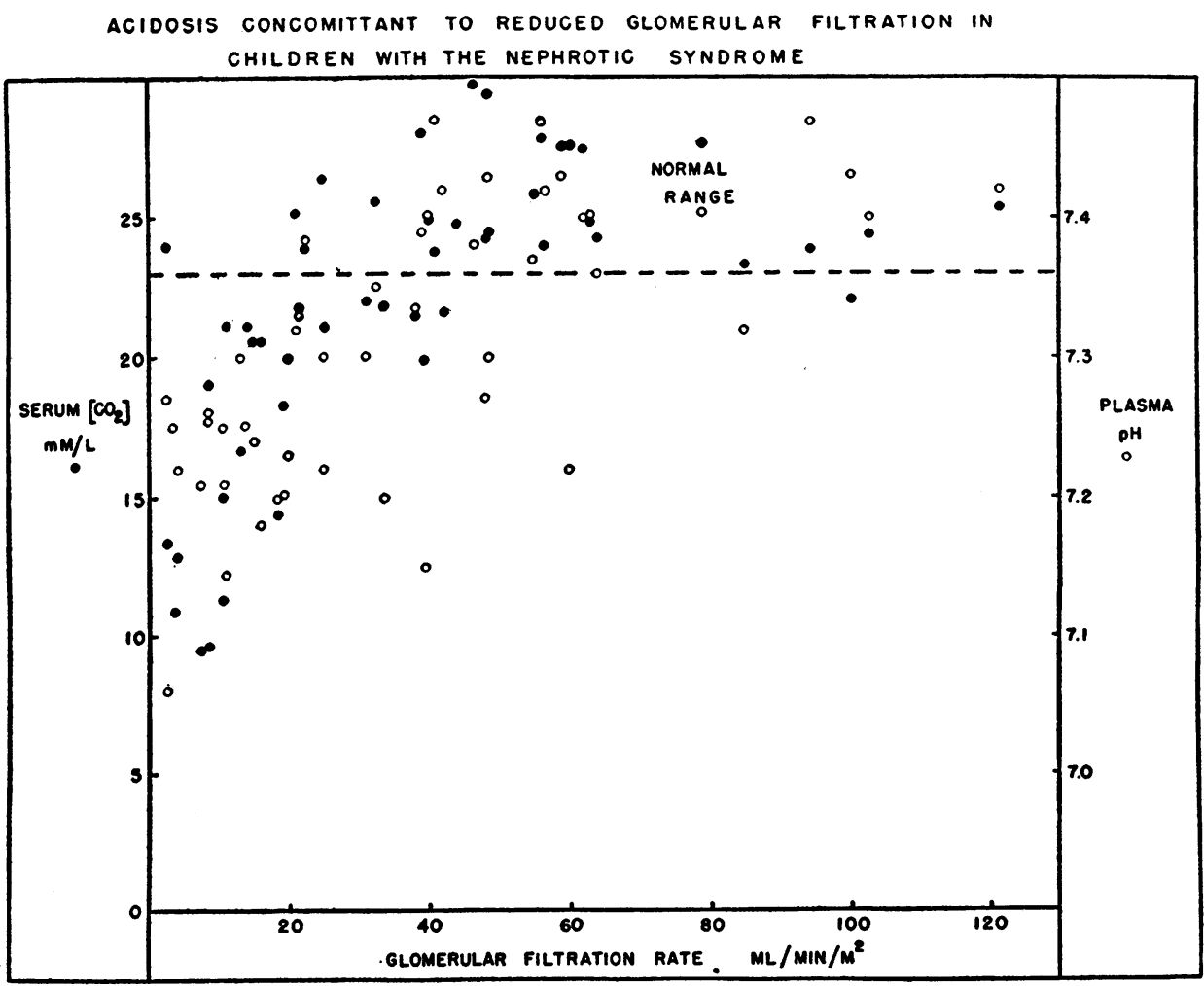

Fig. 2. 
to the buffer base concept suggested by Singer and Hastings (37) (Figure 3). In approximately half of the patients, whole blood buffer base was estimated. In these instances, the derived values were slightly different; the trend and relationships were the same. It was evident that reduction of serum buffer base was usually associated with reduced GFR; however, reduction of GFR was observed occasionally without concomitant lowering of serum buffer base. Anemia, when accompanying azotemia and acidosis, completed a triad which indicated marked limitation of renal regulation and suggested a very poor prognosis. Anemia is rare early in the nephrotic syndrome. These three variables, rather arbitrarily related to each other, have been expressed as a ratio and correlated with GFR (Figure 4). The limitations of such an expression are obvious. In most instances, reduction in the arbitrary ratio accompanied roughly proportional reduction in GFR. However, one child (No. 24), ${ }^{8}$ with moderate reduction in the arbitrary ratio after 17 months of active disease, appeared to be in clinical remission approximately one year later although functional data suggested residual renal damage. Several children with very low ratios

8 Here and elsewhere, patients' numbers are as in Tables II and III. have died (Nos. $5,11,18,23,26,28$ ) ; the others have persistent nephrotic symptoms and ample evidence of renal insufficiency.

\section{Renal function data}

The pertinent renal function data for each patient are presented in Table III and may be correlated with the clinical and biochemical observations in Table II. The validity of the "clearance" concept in the presence of nephron damage has been justifiably questioned $(38-40)$. Some data on the response to adrenocorticotropic hormone (ACTH) therapy is included since ACTH may indirectly alter the metabolic activity of viable nephron cells $(41,42) .^{\circ}$ It can hardly be expected to restore destroyed, fibrosed or hyalinized tissue. Therapeutic response, therefore, affords one possible means of contrasting reversible impairment of function with irreversible destruction of parenchyma.

\section{Glomerular filtration rate.}

The distribution of values for GFR in relation to the duration of the disease is depicted in Figure 5. The course of certain patients is indicated. In

${ }^{9} \mathrm{~A}$ detailed report concerning physiologic and clinical response to $\mathrm{ACTH}$ is in preparation.

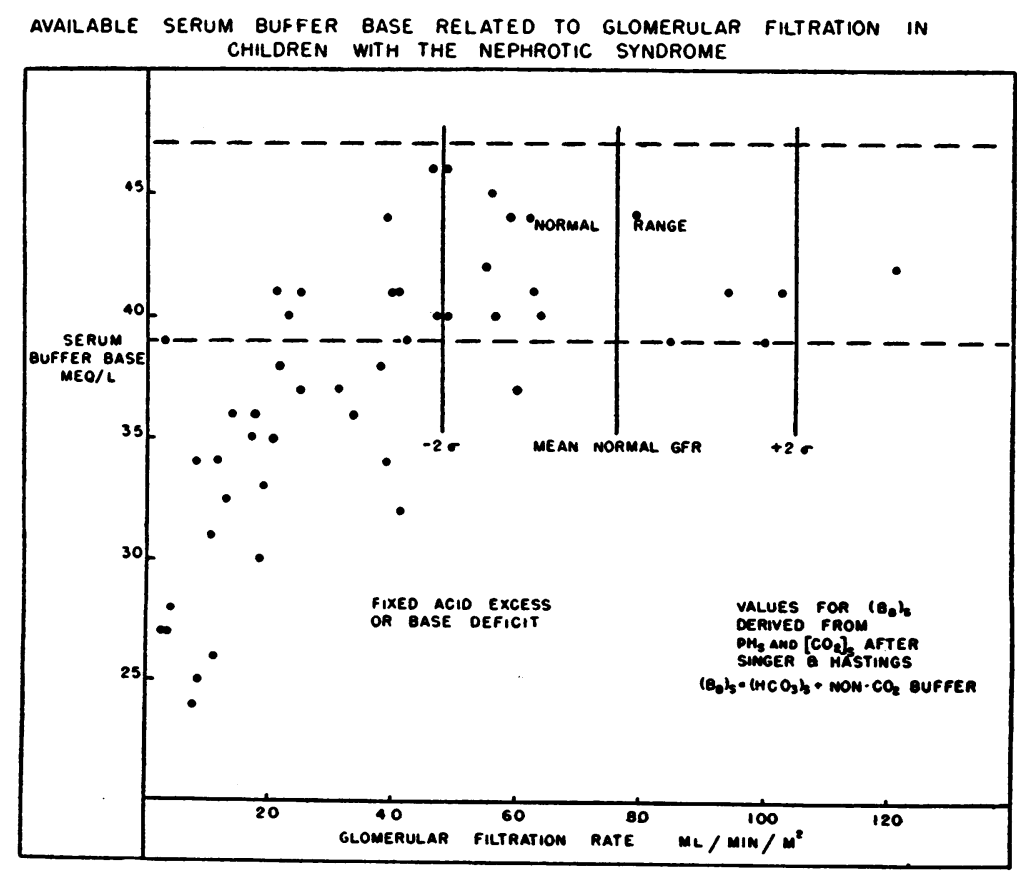

FIG. 3. 
RELATION OF HEMOGLOBIN, SERUM NON-PROTEIN NITROGEN Q BUFFER BASE TO GLOMERULAR FILTRATION RATE IN CHILDREN WITH THE NEPHROTIC SYNDROME

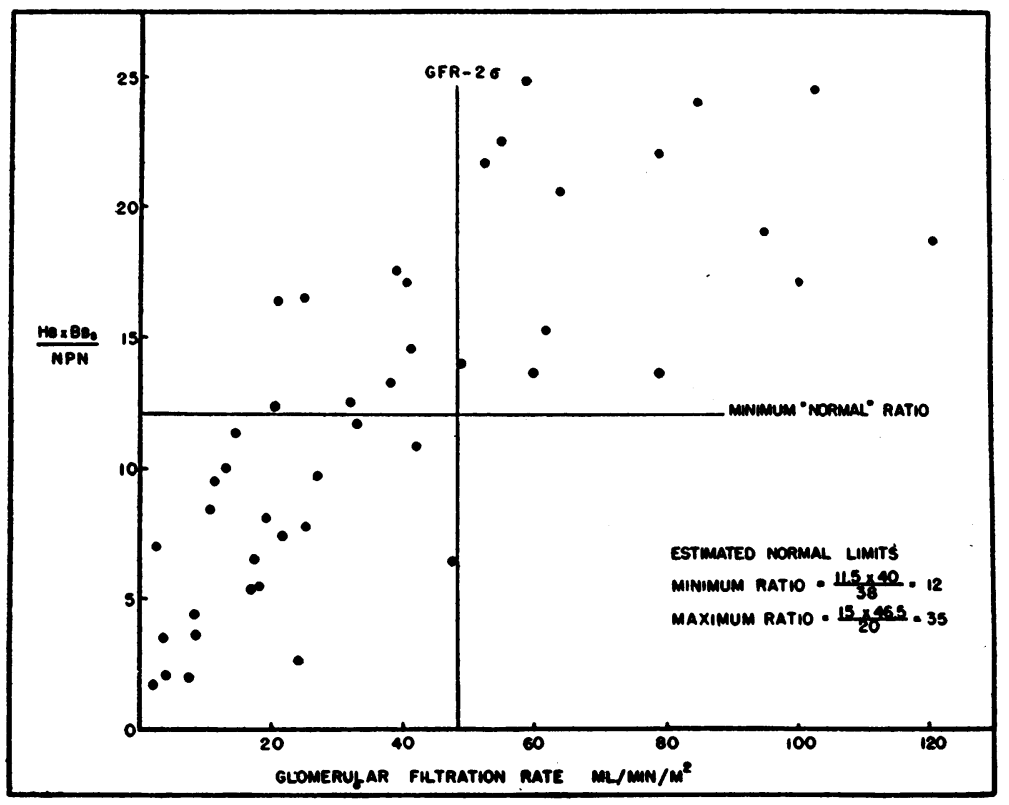

Fic. 4.

RELATION OF glomerular FILTRATION RATE tO DURATION OF THE NEPHROTIC SYNOROME IN CHILDREN

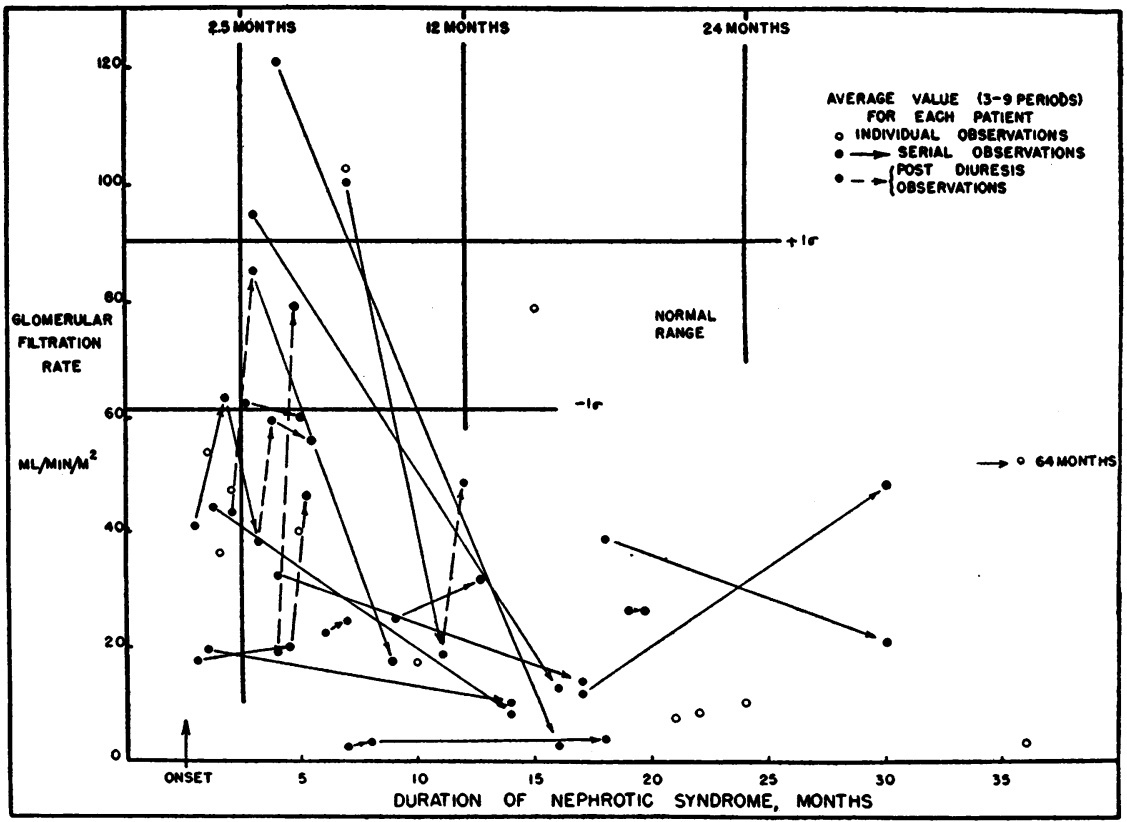

FIG. 5. 


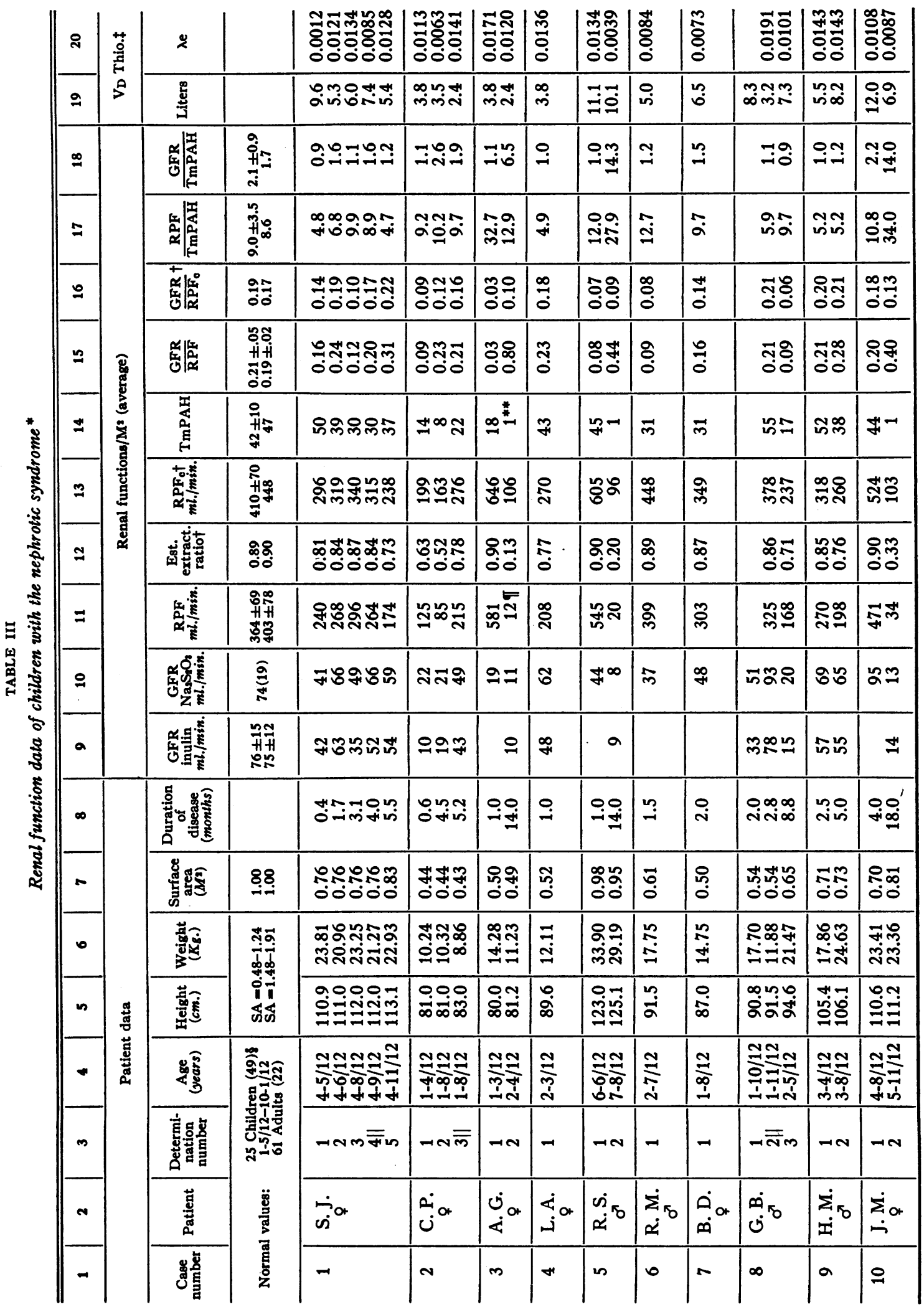




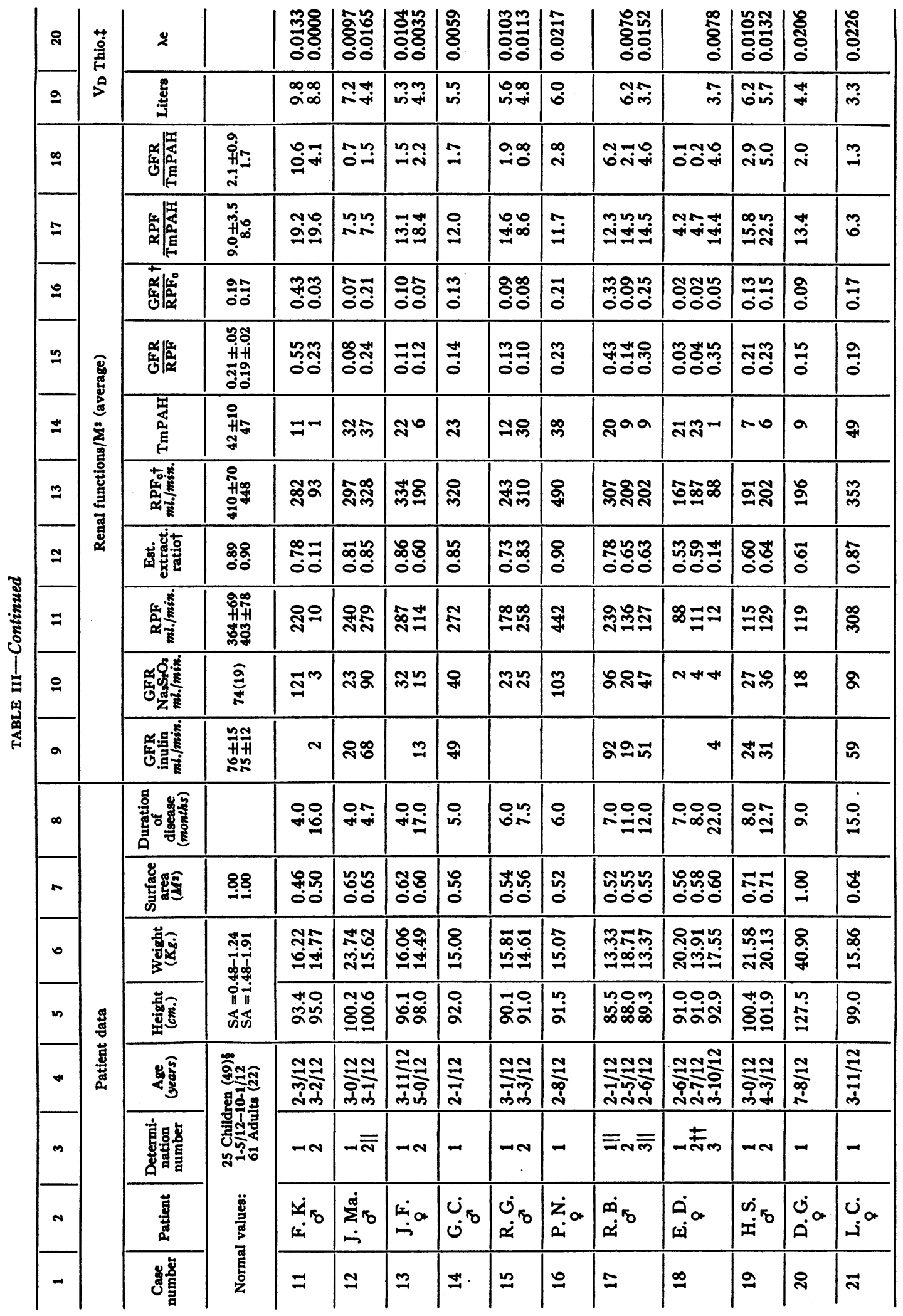


THE NEPHROTIC SYNDROME IN CHILDREN

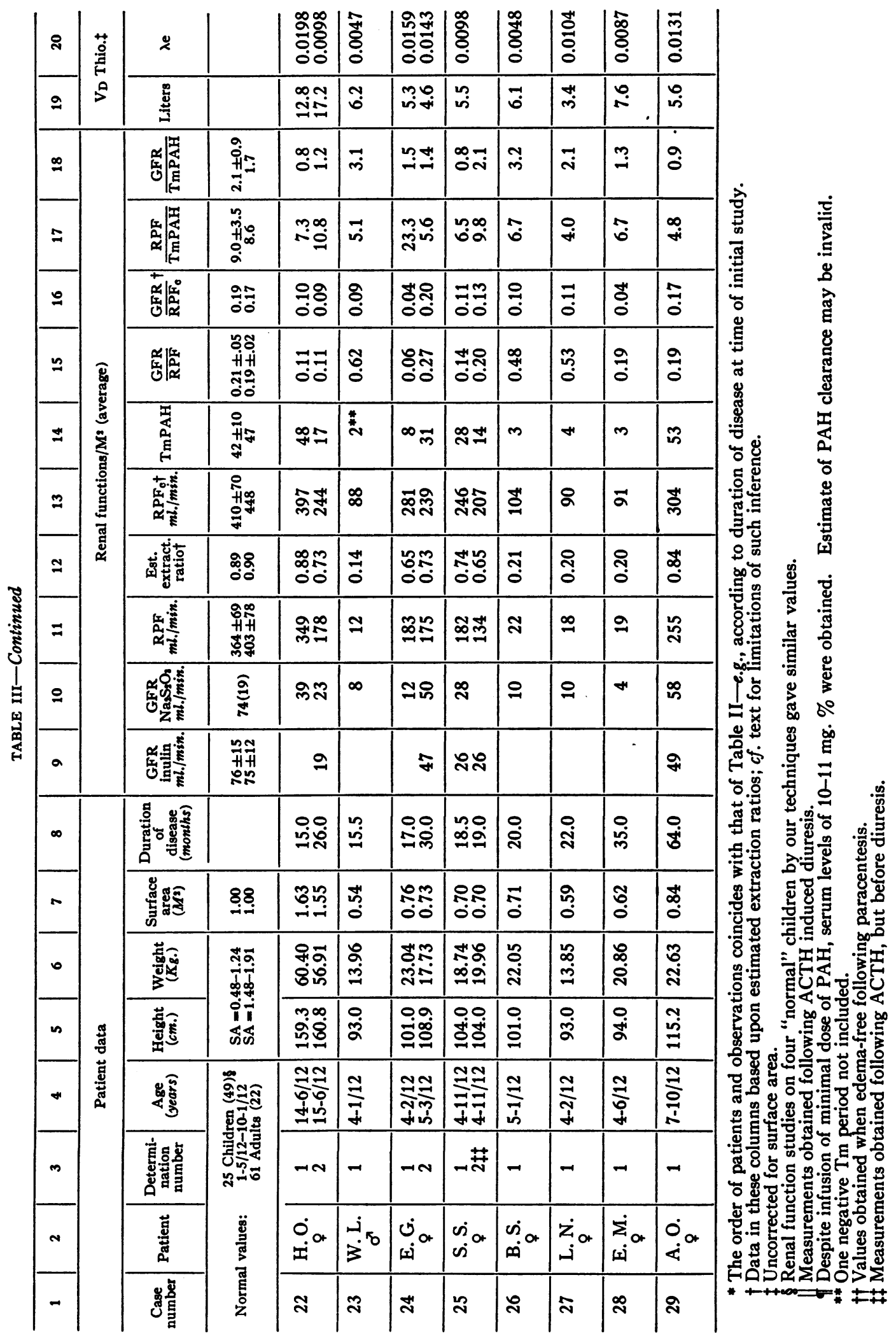




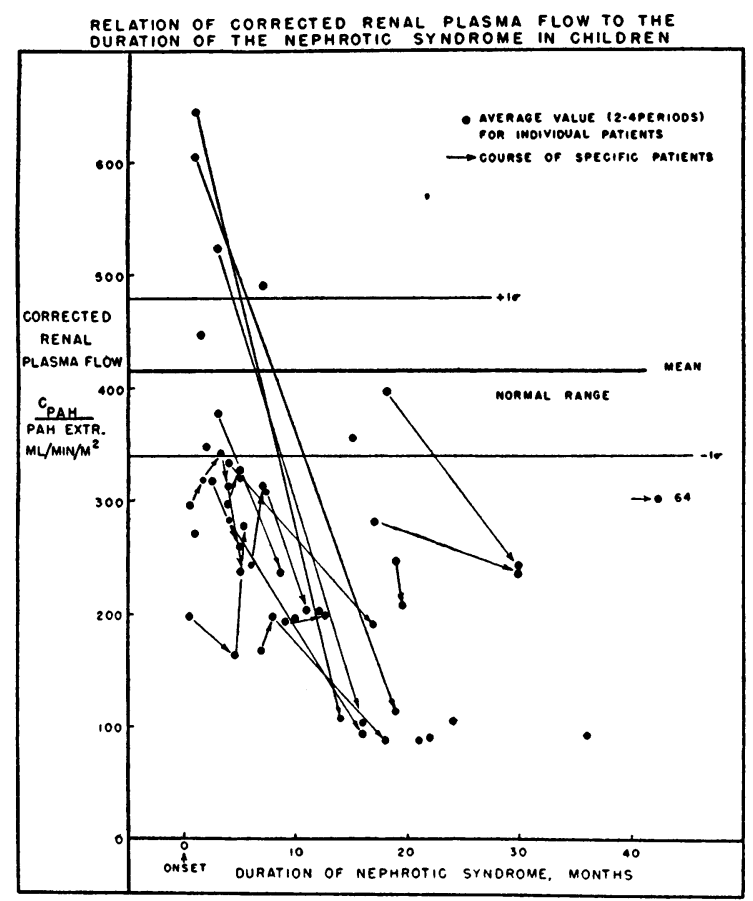

Fig. 6.

general, glomerular function in the nephrotic syndrome varied with duration of the disease. Uniformly reduced filtration rates were noted in nine patients observed during the initial 2.5 months of the disease. Occasionally, supernormal values were noted in the following few months. More commonly, progressive reduction occurred.

Diuresis, which occurs spontaneously in many nephrotic children during the first weeks or months of the disease, usually was associated with improvement of GFR. Increased GFR and filtration fraction were not essential to initiate diuresis (42). In one instance (No. $\left.1_{2}\right),{ }^{10}$ the initial diuresis was spontaneous; in others (Nos. $8_{2}, 12_{2}, 17_{1,3}$ ), it followed ACTH therapy. Following the initial diuresis and during the phase of recurring edema (Nos. $1_{3}, 8_{3}$ ) reduced filtration was again noted. Four instances of supernormal filtration rates were observed after the first two months of the nephrotic syndrome. In one patient (No. 17 $)$, the observation was preceded by diuresis initiated with $\mathrm{ACTH}$ therapy. In others, (Nos. 10,11, 16), no therapy had been employed. Subsequent determinations (Nos. $17_{2}, 10_{2}, 11_{2}$ ) revealed striking reduction of

\footnotetext{
10 Subscript refers to determination number of a given patient; in this instance, to the second renal function study of patient S. J.
}

filtration. An increase in filtration rate was observed twice in the same patient (Nos. $1_{4}, 17_{3}$ ) following successive courses of treatment with ACTH with diuresis. Spontaneous or ACTH induced improvement of GFR after many months of active disease was also noted twice (Nos. 19, 24, ).

With continuation of the disease, progressive lowering of GFR was ultimately associated with renal failure. Extreme reduction in GFR was noted $\left(\right.$ No. $\left.18_{1,2}\right)$ for many months before clinical evidence of renal failure became apparent. Demonstration of diminished filtration after 17 months of active disease did not preclude apparent clinical remission, (No. 24). Subsidence of nephrotic symptoms and signs after a protracted course was usually characterized by persistent evidence of minimal inflammatory renal response and slightly reduced GFR (Nos. 17, 24, 29). Relatively early clinical remission was accompanied by normal GFR (No. 21).

\section{Renal plasma flow}

Unlike GFR, greater than normal values for apparent renal plasma flow were occasionally observed during the first months of the disease (Figure 6). Marked elevation of renal plasma flow was observed concomitantly with supernormal GFR (Nos. 10, 16) as well as with moderately (No. $5_{1}$ ), or markedly (No. 3 ) reduced GFR. In several instances, elevation of the filtration rate was associated with diminution of renal plasma flow (Nos. $11_{1}, 17_{1}$ ). It was evident that change in renal plasma flow could occur without significant variation in GFR (Nos. $\left.1_{5}, 3,9,15,18,22\right)$. The reverse also was true (Nos. 1, 12, 17).

Following diuresis, either spontaneous (No. $1_{2}$ ) or induced (Nos. $1_{4}, 17_{3}, 12_{2}$ ), a definite increase in renal plasma flow usually was not observed. In one instance (No. 2 , $_{3}$, RPF was apparently doubled. While normal values were occasionally noted with apparent clinical remission (Nos. 12, 21 ), reduced renal plasma flow was also observed (Nos. 24, 29). Persistence of the nephrotic syndrome was usually associated with progressive reduction in both measured and "corrected" renal plasma flow (Nos. $5,8_{3}, 13,17_{2}, 18,22$ ).

\section{Maximal tubular excretory capacity}

Maximal tubular excretory capacity was usually within normal limits or was slightly reduced during 
RELATION OF MAXIMAL TUBULAR EXCRETORY CAPACITY TO DURATION OF THE NEPHROTIC SYNDROME IN CHILOREN

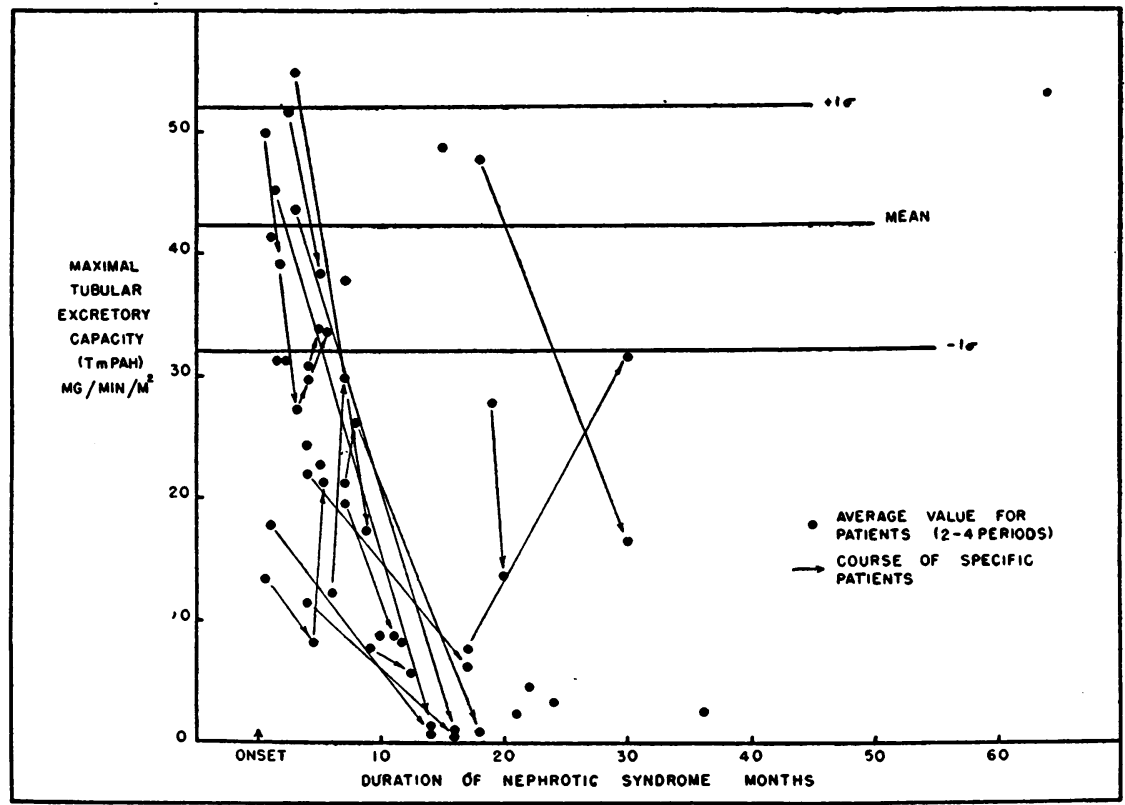

Fig. 7.

the first months of the disease (Figure 7). Neither spontaneous nor ACTH induced diuresis commonly was associated with significant alteration in this function (Nos. $1_{2,4}, 12_{2}, 17_{3}$ ) except in $\left(\right.$ No. $2_{3}$ ). Early reduction in maximal tubular excretory capacity was apparently reversible, (Nos. $2_{3}, 15_{2}$ ). With persistence of the disease, progressive reduction in $\mathrm{Tm}_{\mathrm{PAH}}$ was observed. With clinical remission, despite a protracted course, normal values were observed (Nos. 21, 24, 29). Tubular reabsorption of $\mathrm{PAH}$ possibly accounts for the occasional observation of negative Tm periods (Nos. 3, 23) or apparent extreme reduction of effective tubular mass (Nos. 5, 10, 11, 18, 26-28). ${ }^{11}$

\section{DISCUSSION}

Marked distortion of the nephron and its supporting structures with extreme variation in architecture is not common in the early phases of the nephrotic syndrome in children $(43,44)$. In instances where death has resulted from intercurrent infection in the early months of the disease,

11 Despite rising serum PAH and inulin levels, consecutive periods commonly revealed little change in Tm although a slight tendency toward depression of simultaneous inulin clearance was noted. the absence of striking morphologic changes, particularly of the glomerulus, has been evident ( 9 , 11). Our data indicate a slight to moderate reduction of glomerular filtration early in the course of the nephrotic syndrome. Filtration is largely the resultant of hydrostatic pressure in one direction, oncotic and renal interstitial pressure in the other, and of the area over which the resultant pressure is exerted. Changes in effective renal arteriolar resistance may modify filtration $(45,46)$. The ratio of glomerular filtration to renal plasma flow (filtration fraction) defines the filtration equilibrium. Early in the nephrotic syndrome, the filtration fraction (FF) occasionally was observed to be essentially normal ; rarely, it was markedly elevated; most commonly it was reduced (Figure 8 ). Renal plasma flow was usually reduced early in the disease, but filtration appeared to suffer greater proportionate reduction, although inconstant dissociation of the two functions was evident (Figure 9). The relationship between the two variables is illustrated by means of a correlation diagram of the sort employed by Goldring and his associates (47) and Smith (48). In this diagram, the elipse represents the perimeter of a normal surface within which $70 \%$ of normally correlated values would 
be expected to fall. The statistical background for the elipse was calculated from the data of Rubin, Bruck, and Rapoport (49). Spontaneous or induced (ACTH) improvement of the nephrotic syndrome was usually associated with an increased filtration fraction. An absolute increase of GFR usually was responsible. Plasma protein concentration (or content) did not appear to undergo appreciable diminution with diuresis, and possibly increased. Therefore, further reduction of oncotic pressure accounting for increased filtration seemed unlikely. An increased filtration fraction associated with reduced afferent and augmented efferent arteriolar resistance has been observed with diuresis in nephrotic edema (42). Improved filtration during the nephrotic syndrome might result from decreased interstitial renal (subcapsular) pressure, alteration in membrane permeability, increase of the effective glomerular bed by restoration of normal circulatory channels, or by increase in glomerular pressure. It is not possible to choose between these alternatives at present. Since reduced GFRs were demonstrably reversible for variable periods of time, a disease process irreversibly obliterating glomeruli during the relatively early phases of the nephrotic syndrome seems unlikely. Persistence of the nephrotic syndrome with evidence of active renal disease for some period of time usually was associated with gradual reduction in all functional moities. When, in cases of the protracted nephrotic syndrome progressive diminution of filtration fraction was observed, associated changes in $R P F / T m_{P A H}$ and GFR/ $T_{\text {PAB }}$ suggested extensive nephron damage. These observations are consistent with those reported in glomerulonephritis $(14,15)$.

Increased maximal tubular excretory capacity following diuresis was occasionally observed in the first few months of the nephrotic syndrome. These observations suggest increased activity of the tubular cell. It has been demonstrated that the excretory capacities of the tubular cell may be altered under certain conditions (50). In either case, the concept of primary degenerative, irreversible change of the tubular tissue seems untenable. With clinical remission following many months of an active, persistent nephrotic syndrome, the effective tubular mass appeared to be essentially normal or only slightly reduced. With relapse, or progressive, active disease, reduction of $\mathrm{Tm}$ appeared to correlate with relatively symmetrical reduction of GFR (Figure 10). This phenomenon has been interpreted as evidence for ablation of functioning nephrons (48). The simultaneous appearance of biochemical renal insufficiency (Table II) tended to corroborate this interpretation. Reduction of

RELATION OF FILTRATION FRACTION TO DURATION OF DISEASE IN CHILDREN

WITH THE NEPHROTIC SYNDROME

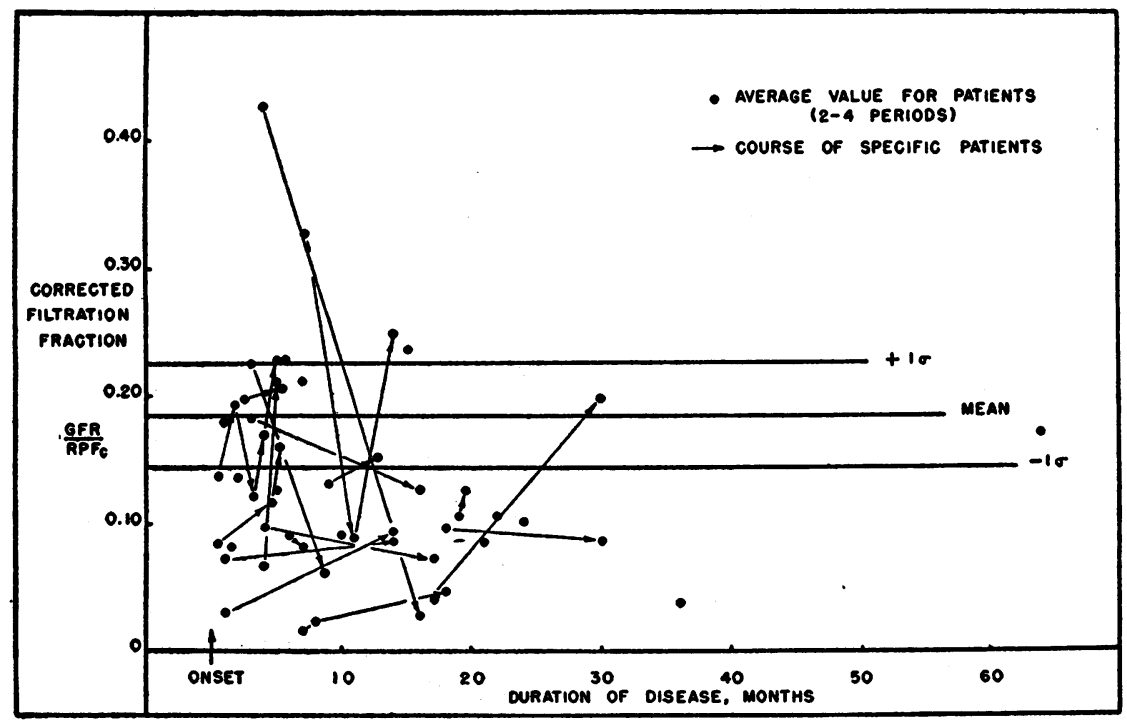

FIG. 8. 
RELATION OF GLOMERULAR FILTRATION TO RENAL PLASMA FLOW IN CHILDREN

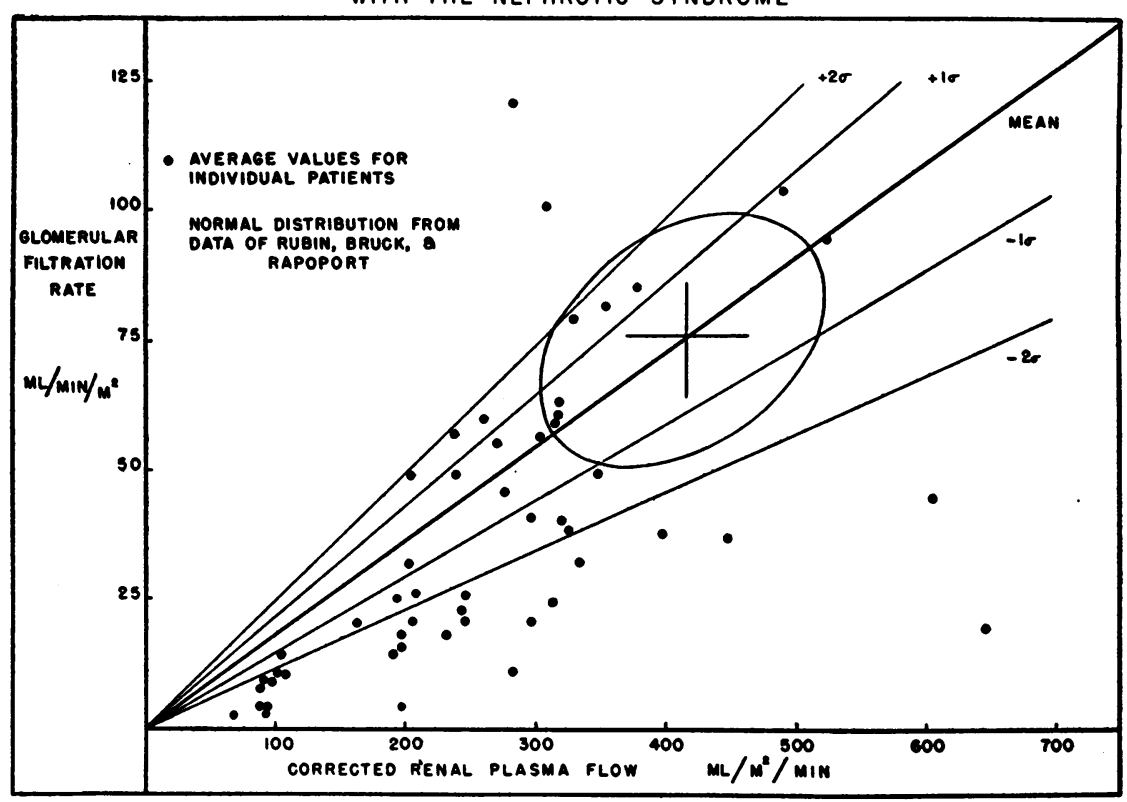

Fig. 9.

effective tubular mass, however, appeared disproportionately greater than diminution of renal plasma flow (Figure 11), suggesting hyperemia of the residual tubular tissue. In view of pathologic studies indicating distortion, vascular obliteration (51), and relative renal ischemia in advanced renal disease $(15,52)$, it seems likely that the apparent hyperemia is vicarious.

Neither the clinical observations nor the renal functional data clarify the etiology or pathogenesis of salient features of the nephrotic syndrome such as edema, hyperlipemia, hypoproteinemia or hypocalcemia. However, the data of this report form the basis for an hypothesis concerning the renal hemodynamic adjustments in the nephrotic syndrome in children (Figure 12). The validity of clearance measurements in the presence of nephron disease and at very reduced levels of renal function is uncertain and interpretation hazardous. With this reservation, further qualified by limitations of sampling and the necessity for protracted observation, it is suggested that the initial renal insult, which may be of immunogenic nature (53), involves the entire nephron in variable degree, with early alteration of its functional capacities. Preponderance of glomerular or tubular dysfunction may be observed. Initial reduction of GFR and
FF may be contingent upon increased renal interstitial pressure, impaired glomerular membrane permeability, cortico-medullary shunts bypassing some glomeruli, or reduction of glomerular pressure. Diminished oncotic pressure would tend to improve glomerular filtration. Physiologic adjustment might attend reduction of subcapsular and increased intra-glomerular pressures. Constriction of the efferent arterioles, if associated with some dilatation of the afferent arterioles, reduced renal interstitial pressure and minimal alteration of the glomerular membrane, could theoretically induce supernormal glomerular filtration. Successful adjustment of the metabolic activities of tubular cells might result in diuresis and at least temporary remission. Recovery would follow successful, persistent functional reorganization of the nephron before irreversible anatomic damage was established. Failing functional reorganization, or possibly with recurrent stimulation of sensitized renal tissues by a primary etiologic agent, gradual distortion of the vascular architecture and dependent nephron structures characteristic of chronic renal disease might then initiate a vicious cycle of glomerular obliteration with diminished tubule blood flow and vascular shunting. Relatively increased blood flow adjacent to residual tubular tissue would thus represent 
RELATION OF GLOMERULAR FILTRATION RATE TO EFFECTIVE TUBULAR MASS IN CHILOREN WITH THE NEPHROTIC SYNDROME

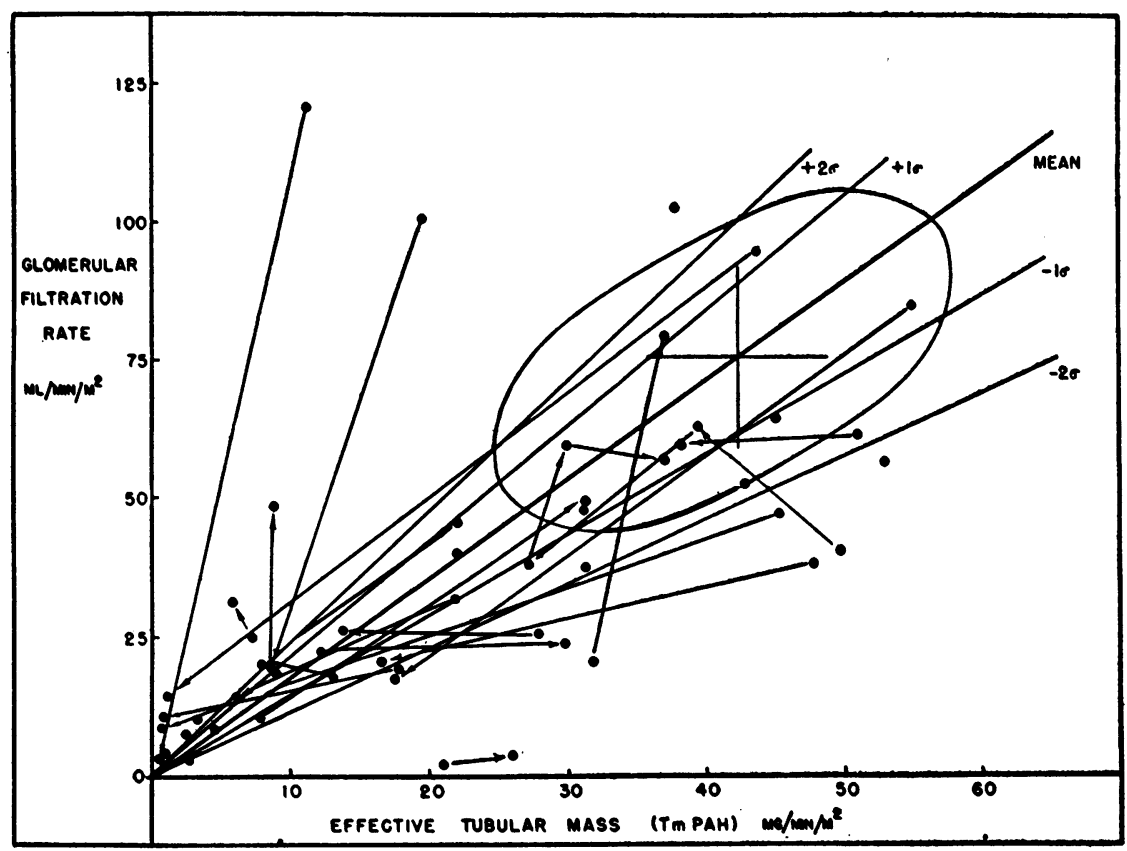

Fig. 10.

- relation of renal plasma flow to effective tubular mass in chiloren WITH THE NEPHROTIC SYNDROME

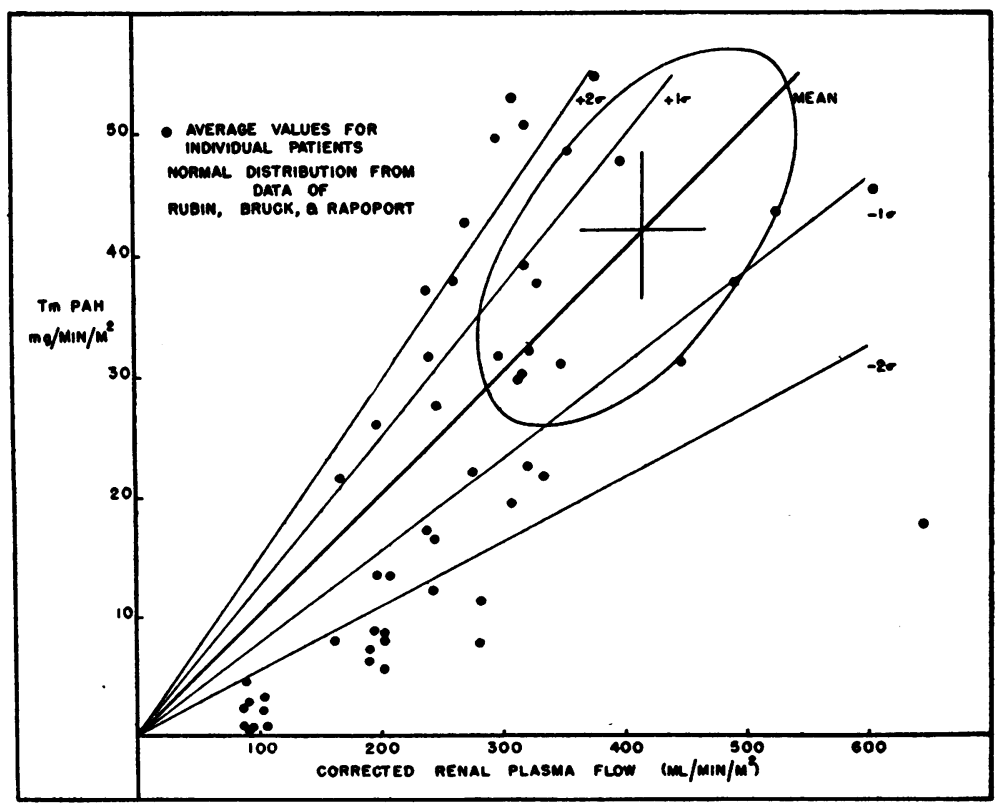

Fig. 11. 


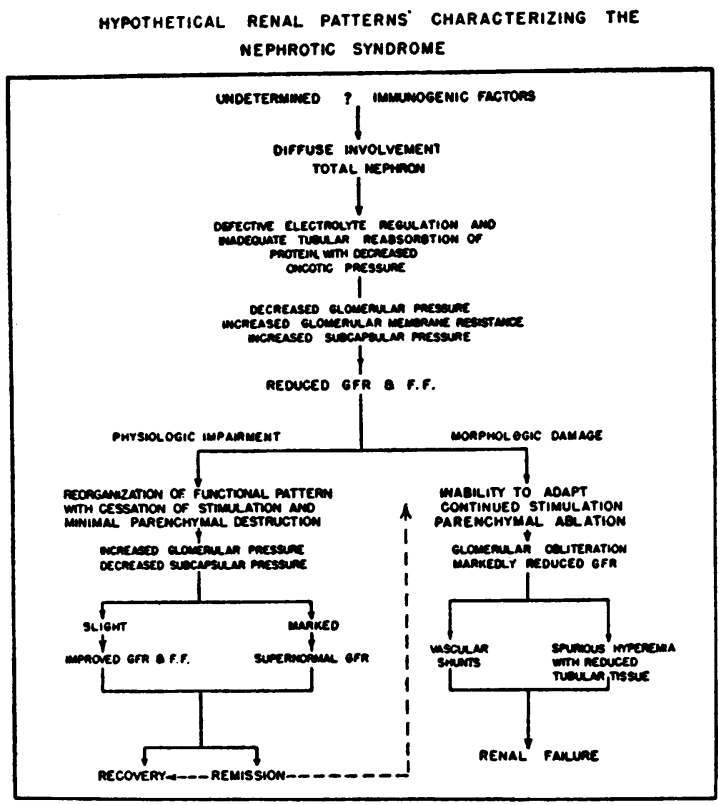

FIG. 12.

a spurious hyperemia and an indication of impending renal failure.

Since young children, unlike older patients, often recover following the nephrotic syndrome, the more favorable tissue reactivity of the young organism may explain the different course of this disease in these two age groups.

\section{SUMMARY AND CONCLUSIONS}

Twenty-nine children with the nephrotic syndrome, a fairly typical sample of 90 patients recently observed, have been studied by clinical, biochemical, and renal function techniques.

Conventional clinical criteria frequently proved unreliable early in the course of the nephrotic syndrome as indices of the functional status of the kidney or as guides to the subsequent course of the patient. The triad of anemia, acidosis, and azotemia, when correlated with a diminished GFR, indicated incompetence of the nephron for biochemical regulation and probable morphologic damage with poor prognosis.

Fluctuating changes in GFR, $R P F$, and $T_{m_{P A B}}$ during the nephrotic syndrome suggested that variations in these measurements are a function of the severity and duration, rather than type, of disease. The biochemical and renal functional patterns indicate that reversible metabolic and hemo- dynamic rather than irreversible anatomic nephron damage frequently occurs. With progressive disease of long duration, markedly impaired renal function suggested that irreversible parenchymal destruction gradually supersedes the earlier physiologic changes, with culmination in renal failure.

The primary etiologic mechanism remains undetermined; however, the idiopathic nephrotic syndrome in children, whether called "pure or lipoid nephrosis," "mixed nephritis," or "nephrotic stage of subacute or chronic glomerulonephritis," appears to be a form of nephritis in which functional alteration and eventual anatomical changes indicate that the glomerulus is a primary site of the disease process. With inhibition of the unknown etiologic mechanism presumably before extensive anatomic damage has supervened, spontaneous or induced remissions may proceed to apparent recovery.

\section{ACKNOWLEDGMENTS}

We are deeply indebted to the house staff, the nursing staff and the clinical laboratories of the Children's Medical Center for their cooperation and assistance in the care of these children. We also wish to acknowledge the valuable assistance rendered by Lewis $A$. Barness and Malcolm Holliday in some of the initial renal function procedures. The manuscript profited from the constructive criticism of Drs. Herbert Chasis and Homer W. Smith. We sincerely appreciate their comments.

\section{REFERENCES}

1. Bradley, S. E., and Tyson, C. J., Medical Progress; The "nephrotic syndrome." New England J. Med., 1948, 238, 223 and 260.

2. Emerson, K., Jr., Futcher, P. H., and Farr, L. E., The relation of high and low urea clearances to the inulin and creatinine clearances in children with the nephrotic syndrome. J. Clin. Invest., 1941, 20, 361.

3. Leiter, L., Nephrosis. Medicine, 1931, 10, 135.

4. Aldrich, C. A., Nephritis, in Practice of Pediatrics, edited by Brennemann, J. W. F. Prior, Co., Inc., Hagerstown, Md., 1944, Vol. 3, Chap. 28, p. 1.

5. Lyttle, J. D., and Goettsch, E., Nephritis and Nephrosis, in Practice of Pediatrics, Brennemann. W. F. Prior Co., Inc., Hagerstown, Md., 1946, Vol. 3, Chap. 28, p. 13.

6. Blackfan, K. D., and McKhann, C. F., Nephritis in childhood, in Oxford Medicine, edited by Christian, H. A., and Mackenzie, J. Oxford U. Press, N. Y., 1929, Vol. 3, p. 772.

7. Heymann, W., and Startzman, V., Lipemic nephrosis. J. Pediat., 1946, 28, 117. 
8. Schwartz, H., Kohn, J. L., and Weiner, S. B., Lipoid nephrosis; observations over a period of 20 years. Am. J. Dis. Child., 1943, 65, 355.

9. Block, W. M., Jackson, R. L., Stearns, G., and Butsch, M. P., Lipoid nephrosis; clinical and biochemical studies of 40 children, with 10 necropsies. Pediatrics, 1948, 1, 733.

10. Barness, L. A., Moll, G. H., and Janeway, C. A., Nephrotic syndrome. I. Natural history of the disease. Pediatrics, 1950, 5, 486.

11. Galán, E., Nephrosis in children. I. Observations on 84 patients. II. Clearance and saturation tests. Am. J. Dis. Child., 1949, 77, 328.

12. Farr, L. E., Assimilation of protein by young children with nephrotic syndrome; effect of nephrotic crises on assimilation of nitrogen. Am. J. Dis. Child., 1939, 58, 939.

13. Van Slyke, D. D., Stillman, E., Möller, E., Ehrich, W., McIntosh, J. F., Leiter, L., MacKay, E. M., Hannon, R. R., Moore, N. S., and Johnston, C., Observations on the courses of different types of Bright's disease, and on the resultant changes in renal anatomy. Medicine, 1930, 9, 257.

14. Earle, D. P., Jr., Taggart, J. V., and Shannon, J. A., Glomerulonephritis; a survey of functional organization of the kidney in various stages of diffuse glomerulonephritis. J. Clin. Invest., 1944, 23, 119.

15. Bradley, S. E., Bradley, G. P., Tyson, C. J., Curry, J. J., and Blake, W. D., Renal function in renal diseases. Am. J. Med., 1950, 9, 766.

16. Metcoff, J., Kelsey, W., and Janeway, C. A., The nephrotic syndrome in children. A physiological interpretation based on clearance methods. Am. J. Dis Child., 1950, 80, 524.

17. Blackman, S. S., Jr., On pathogenesis of lipoid nephrosis and progressive glomerulonephritis. Bull. Johns Hopkins Hosp., 1935, 57, 70.

18. Davies, J. A. V., Method of collecting small blood specimens, with special reference to microflocculation tests for syphilis. J. Lab. \& Clin. Med., 1938, 23, 1206.

19. Newman, E. V., Gilman, A., and Philips, F. S., The renal clearance of thiosulfate in man. Bull. Johns Hopkins Hosp., 1946, 79, 229.

20. Lambiotte, C., Blanchard, J., and Graff, S., Thiosulphate clearance in pregnancy. J. Clin. Invest., 1950, 29, 1207.

21. Roe, J. H., Epstein, J. H., and Goldstein, N. P., A photometric method for the determination of inulin in plasma and urine. J. Biol. Chem., 1949, 178, 839.

22. Goldring, W., and Chasis, H., Hypertension and Hypertensive disease. The Commonwealth Fund, N. Y., 1944.

23. Chasis, H., Redish, J., Goldring, W., Ranges, H. A., and Smith, H. W., The use of sodium p-aminohippurate for the functional evaluation of the human kidney. J. Clin. Invest., 1945, 24, 583.

24. Baldwin, D. S., Schreiner, G. E., Breed, E. S., Wesson, L. G., Jr., and Maxwell, M. H., Depression of apparent p-aminohippurate extraction ratio by glucose. J. Clin. Invest., 1950, 29, 614.

25a. Cargill, W. H., The measurement of glomerular and tubular plasma flow in the normal and diseased human kidney. J. Clin. Invest., 1949, 28, 533.

b. Morse, M., Cassels, D. E., and Schlutz, F. W., Available and interstitial fluid volumes of normal children. Am. J. Physiol., 1947, 151, 438.

26. Scheinberg, I. H., and Kowalski, H. J., The binding of thiocyanate to albumin in normal human serum and defibrinated blood with reference to the determination of thiocyanate space. J. Clin. Invest., 1950, 29, 475.

27. Folin, O., Laboratory Manual of Biological Chemistry with Supplement. D. Appleton-Century Co., Inc., N. Y., 1934, 5th edition, p. 271.

28. Van Slyke, D. D., and Neill, J. M., The determination of gases in blood and other solutions by vacuum extraction and manometric measurement. J. Biol. Chem., 1924, 61, 523.

29. Hastings, A. B., and Sendroy, J., Jr., Studies of acidosis. XX. The colorimetric determination of blood $\mathrm{pH}$ at body temperature without buffer standards. J. Biol. Chem., 1924, 61, 695.

30. Bloor, W. R., Pelkan, K. F., and Allen, D. M., Determination of fatty acids (and cholesterol) in small amounts of blood plasma. J. Biol. Chem., 1922, 52, 191.

31. Chinard, F. P., and Eder, H. A., The determination of the concentration of the dye T-1824 in normal and lipemic plasmas. J. Exper. Med., 1948, 87, 473.

32. MacKay, E. M., and MacKay, L. L., Relation between the blood urea concentration and the amount of functioning renal tissue. J. Clin. Invest., 1927, 4, 127.

33. Gamble, J. L., Chemical Anatomy, Physiology and Pathology of Extracellular Fluid. Harvard Univ. Press, Cambridge, Mass., 1950.

34. Chasis, H., and Smith, H. W., The excretion of urea in normal man and in subjects with glomerulonephritis. J. Clin. Invest., 1938, 17, 347.

35. Bulger, H. A., Peters, J. P., Eisenman, A. J., and Lee, C. L., Total acid-base equilibrium of plasma in health and disease. VII. Factors causing acidosis in chronic nephritis; a preliminary report. J. Clin. Invest., 1925-26, 2, 213.

36. Peters, J. P., Salt and water metabolism in nephritis. Medicine, 1932, 11, 435.

37. Singer, R. B., and Hastings, A. B., An improved clinical method for the estimation of disturbances of the acid-base balance of human blood. Medicine, 1948, $27,223$.

38. Smith, H. W., Note on the interpretation of clearance methods in the diseased kidney. J. Clin. Invest., 1941, 20, 631.

39. Herrin, R. C., Factors affecting the tests of kidney function. Physiol. Rev., 1941, 21, 529.

40. Oliver, J., When is the kidney not a kidney? J. Urol., 1950, 63, 373. 
41. Barnett, H. L., McNamara, H., McCrory, W., Forman, C., Rapoport, M., Michie, A., and Barbero, G., The effects of ACTH and cortisone on the nephrotic syndrome. Am. J. Dis. Child., 1950, 80, 519.

42. Metcoff, J., Kelsey, W., Rance, C. P., and Janeway, C. A., Effects of ACTH on the pathologic physiology and clinical course of the nephrotic syndrome in children, in Proc. 2nd Clin. Conf. on ACTH, 1950, edited by Mote, J. R. To be published.

43. Wolbach, S. B., and Blackfan, K. D., Clinical and pathological studies on so-called tubular nephritis (nephrosis). Am. J. M. Sc., 1930, 180, 453.

44. Bell, E. T., Lipoid nephrosis. Am. J. Path., 1929, 5, 587.

45. Smith, H. W., Chasis, H., Goldring, W., and Ranges, H. A., Glomerular dynamics in the normal human kidney. J. Clin. Invest., 1940, 19, 751.

46. Lamport, H., Formulae for afferent and efferent arteriolar resistance in the human kidney: An application to the effects of spinal anesthesia. J. Clin. Invest., 1941, 20, 535.
47. Goldring, W., Chasis, H., Ranges, H. A., and Smith, H. W., Effective renal blood flow in subjects with essential hypertension. J. Clin. Invest., 1941, 20, 635.

48. Smith, H. W., Lectures on the kidney. University Extension Division, University of Kansas, Lawrence, Kans., 1943.

49. Rubin, M. I., Bruck, E., and Rapoport, M., Maturation of renal function in childhood: Clearance studies. J. Clin. Invest., 1949, 28, 1144.

50. Mudge, G. H., and Taggart, J. V., Effect of acetate on the renal excretion of $p$-aminohippurate in the dog. Am. J. Physiol., 1950, 161, 191.

51. Oliver, J., New directions in renal morphology; a method, its results, and its future. Harvey Lectures, 1944-45, 40, 102.

52. Bradley, S. E., The Pathologic Physiology of Uremia in Chronic Bright's Disease. American Lecture Series, No. 15. Charles C. Thomas, Springfield, IIl., 1948.

53. Heymann, W., Lipemic nephrosis in rats : description of the disease and studies on the metabolism of the nephrotic kidney. Am. J. Dis. Child., 1950, 80, 523. 